\title{
Bir Gaz Türbin Motoru Kompresör PalesininTi6Al4V Alaşımından Eklemeli Üretim Yöntemi ile İmalatı ve Boyutsal Doğrulaması
}

\author{
Tamer Saraçyakupoğlu ${ }^{1}$
}

\section{ÖZ}

$\mathrm{Bu}$ çalışmada, bir gaz türbin motoruna ait kompresör palesinin, Ti6Al4V alaşımından Eklemeli Üretim (EÜ) yöntemiyle üretimi ve boyutsal doğrulama ölçümleri gerçekleştirilmiştir. Havacılık endüstrisinde yaygın kullanılan Direkt Metal Lazer Sinterleme (DMLS) yöntemi seçilmiştir. İmalattan sonra her bir palede 87 adet olmak üzere toplam 174 yüzey ölçümü gerçekleştirilmiştir. Ölçümlerde, katı modele oranla, $1 \mathrm{Nu}$ 'lı palede ortalama +0,0944/-0,0809 mm arasında, 2 Nu'lı palede ortalama +0,1093/-0,0978 mm değişim olduğu belirlenmiştir. Her iki paledeki geometrik değişimin birbiri ile tutarlı sonuçlar verdiği gözlemlenmiştir. Sonuç olarak, bir uçar-parçanın uçağa takılmasına yönelik uçuşa elverişlilik çalışmaları konusuna girmeden, bir gaz türbin motoru kompresör palelerinin Ti6Al4V alaşımından EÜ yöntemi ile üretilebileceği ortaya konulmuştur.

Anahtar Kelimeler: Gaz Türbin motor, eklemeli üretim, boyutsal doğrulama, direkt metal lazer sinterleme (dmls), kompresör palesi

\section{Manufacture and Dimensional Verification of a Gas Turbine Engine Compressor Blade Produced via Additive Manufacturing Method using Ti6Al4V}

\begin{abstract}
In this study, the production of a compressor blade belonging to a gas turbine engine via Additive Manufacturing (AM) method using Ti6Al4V alloy and dimensional verification measurements were performed. The Direct Metal Laser Sintering (DMLS) method, which is widely used in the aviation industry was chosen. After manufacturing, a total of 174 surface measurements were made, 87 on each blade. In the measurement, it was determined that there is an average deviation of $+0.0944 /-0.0809 \mathrm{~mm}$ in the $1 \mathrm{st}$ blade and $+0.1093 /-0.0978 \mathrm{~mm}$ in the 2nd blade compared to the 3D solid model. It was observed that the geometric deviation of the two blades is consistent with each other. As a result, it has been demonstrated, that compressor blades of a gas turbine engine can be produced via AM method using Ti6Al4V without dealing with the airworthiness studies for manufacturing the airborne part.
\end{abstract}

Keywords : Gas turbine engine, additive manufacturing, dimensional verification, direct metal laser sintering (DMLS), compressor blade

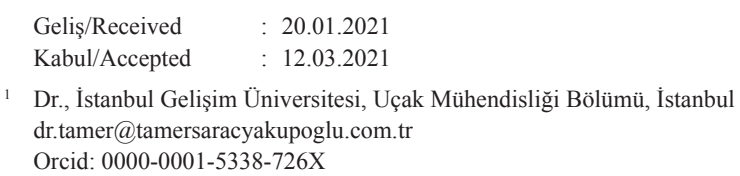




\section{EXTENDED ABSTRACT}

\section{Introduction}

In this study, it is aimed to make a geometric accuracy study of turbojet engines high-pressure compressor blades that have been additively manufactured with Ti6Al4V material. Turbojet engines are the most familiar engines in the aviation industry. In a turbojet engine, there are cold and hot sections. The compressor blade which works under high pressure and cyclic loads were aimed to produce. On the other hand, the parts that are made of Titanium alloys are frequently used in turbojet engines. Because of the relatively lower melting point, the titanium alloy parts are generally used in the cold sections of the engine while nickel and cobalt alloys are preferred in the hot sections. With its layerwise manufacturing technique, the additive manufacturing technology has been selected for this study since it has been widely used in the aviation industry since it provides the ability of complexshaped parts. Direct Melting Laser Sintering (DMLS) is a method of additive manufacturing. The DMLS has been selected since it is one of the most popular additive manufacturing technology currently used widely in the aviation industry.

\section{Research Purpose}

The objective of this research study is to understand the manufacturability of a turbojet engine high-pressure compressor blade using EOSM290 Direct Melting Laser Sintering (DMLS) machine. While focusing on the manufacturability of the blades the limits of the EOSM290 machine was also examined in terms of manufacturing performance. A blade was selected since it has a relatively complex shape, containing curves and sharp edges. During the study, a First Article Inspection (FAI) activity was also performed in accordance with the reference documents provided by EOS company. In terms of manufacturability, not only the additive manufacturing machine but also the heat treatment oven and sand-blasting machines were also examined.

\section{Methods/ Methodology}

Before manufacturing, a work-flow chart was prepared with the coordination of the machine manufacturer and test center. Later on, a work control document that includes the steps was prepared based on the information of the mentioned work-flow chart. Simultaneously, a 3D CAD model of a generic blade that is used on a turbojet engine's high-pressure compressor stage has been created with Catia software. During CAD model preparation, the tight tolerances and outer surface features have been taken into account. It was planned to manufacture two blades for comparing and cross-check the parts with each other. During machining, the layer thickness, laser scan speed, laser power, and hatch distance parameters were used as default values prepared and provided by EOS. After manufacturing, a heat treatment process has been applied to the blades. After heat treatment, the parts were sent to an independent test center for having information about geometrical accuracy and dimensional verification. The independent test center where has a three-dimensional verification system made the inspections in detail. For inspections, the 3D CAD model's data has been provided to the test center.

\section{Results/ Findings}

At the end of the geometrical inspections, it was observed that the two parts are very close to each other in terms of outer shape dimensions. In another meaning, additive manufacturing, sand-blasting, and heat treatment process were providing results promptly. From the open literature studies, it was known that $11 \%-12 \%$ shrinkage is one of the natural results of sintering and needed to be optimized for having the demanded geometrical features and surface roughness. In this manner, it can be claimed that the results were as predicted. 


\section{Discussion and Conclusions}

It was found that the two additively manufactured blades are very close to each other in terms of geometrical features. It can be considered as self-proof of this research study. It is noteworthy, that the steps of the additive manufacturing process and post-process activities are manageable since the results are coherent to each other. For the future studies, with the evaluation of the shrinkage percentage, the 3D model may be modified with bigger sizes on basis of the calculations. Besides, the layer thickness, laser scan speed, laser power, and hatch distance parameters can be optimized in terms of having the prompt part which is demanded. A Hot Isostatic Press (HIP) process may be used for final shaping instead of the heat-treatment oven. Eventually, with additive manufacturing technology, it is possible to produce the parts for turbojet engines. During this process, titanium alloys are eligible for cold sections such as compressors. Other than blades, the vanes, stators, and other engine parts are strong candidates for additive manufacturing technology and titanium alloys. The increasing demand for usage of additively manufactured parts for air vehicle engines gives clues about future implementations. 


\section{GÍRIŞ}

Hava araçları zorlu şartlarda görev yapmak üzere tasarlanmaktadır. Ortalama bir yolcu uçağının seyrüsefer irtifasında dış ortam sıcaklığı $-55 /-60{ }^{\circ} \mathrm{C}$ iken uçağın motorundaki sıcak bölmede ortalama sıcaklık $1600{ }^{\circ} \mathrm{C}$ 'dir [1,2]. Etiyopya'daki Erta'Ale Lava Lake yanardağından çıkan lavın $1187^{\circ} \mathrm{C}$ [3] olduğu göz önüne alındığında bir uçak motoruna yönelik üretim yapılırken nasıl ileri bir teknolojiye gereksinim duyulduğu anlaşılabilmektedir. Kullanım amaçlarına göre askeri, ticari-yolcu, ambulans, yangın söndürme ve zirai ilaçlama uçakları gibi birçok kategoriye sahip olan hava taşıtlarının ortak paydası, üretim yöntemlerinin karmaşık mühendislik hesaplamalarıyla hayata geçirilmiş olmasıdır. Bu sebeple, havacılık sektöründe üretim yapmak, ülkelerin endüstriyel gelişmişliklerinin göstergesi olarak nitelendirilmektedir [4,5]. Havacılık sektöründe üretim yapmak için gerekli olan kurallar ulusal ve uluslararası havacılık otoriteleri tarafından yönergelerle belirlenmiştir. Söz konusu üretim süreci Üretim Organizasyon Onayı (ÜOO, Product Organization Approval-POA) gereklilik-

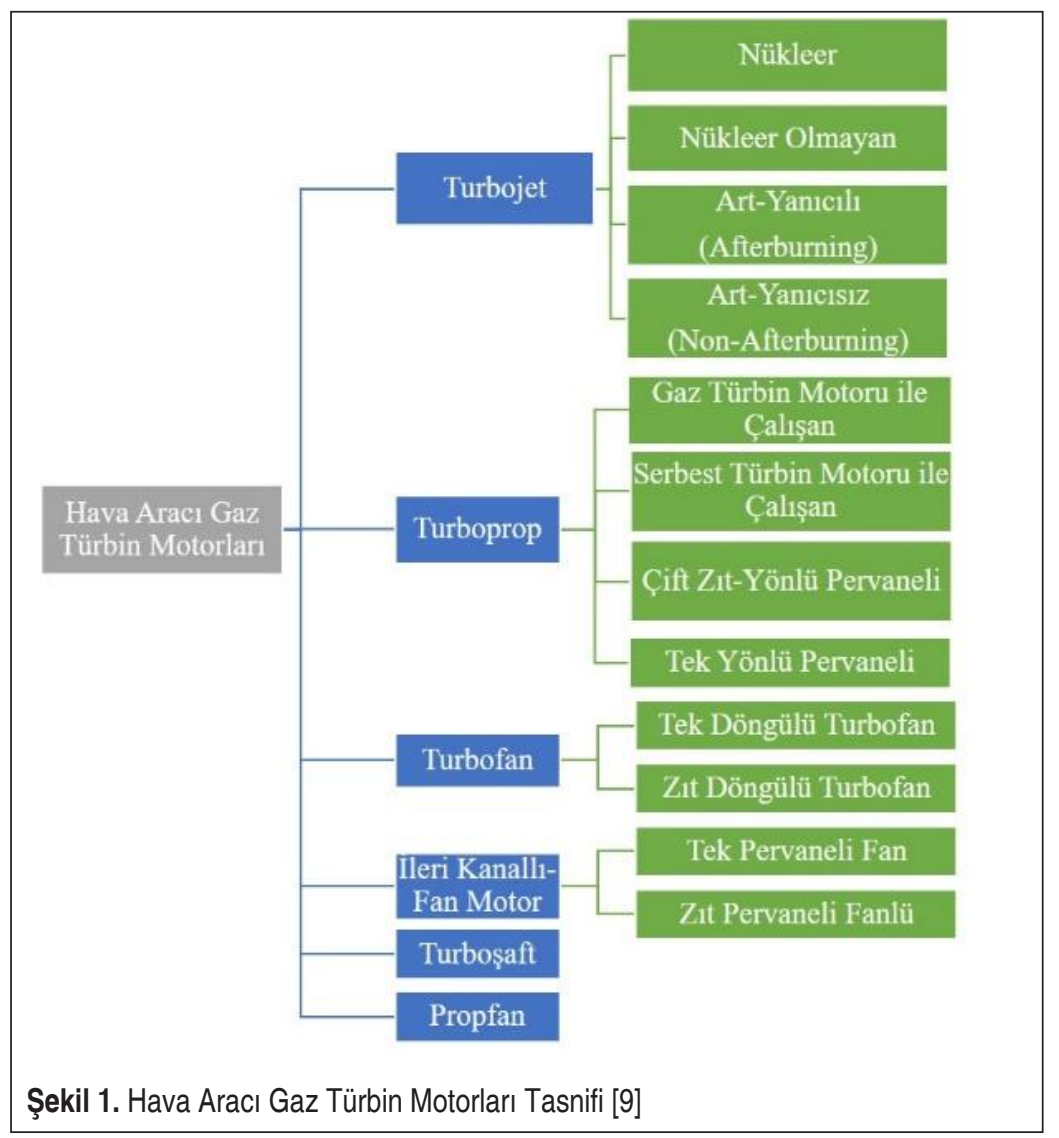


leri olarak Part 21-G şeklinde ifade edilmektedir [6,7,8]. Söz konusu onay sürecinde, üretim yapılan fabrika ortamından, çalışan personelin bilgi donanımı ve tecrübesine kadar bütün gereklilikler dokümante edilmiştir. Bu çalışmanın odağında ÜOO gereklilikleri yer almamakta; sadece imal edilebilirliğe yönelik analizler yapılmaktadır.

Gaz türbin motorları, çalışma şartları ve sistem gereksinimlerine göre kategorize edilmektedir. Şekil 1'de görüldüğü üzere çalışma şartları ve itki üretme yöntemlerine bağlı olarak birçok değişik tipte gaz türbin motoru kullanımı söz konusudur.

Gaz türbin motorları esas olarak kompresör, yanma odası ve türbin modüllerinden oluşmaktadır. Kompresör, motor içerisinde soğuk bölge olarak isimlendirilen kısımda yer alırken, yanma odası ve türbin kısımları ise sıcak bölge adı verilen kısımdadır. Şekil 2'de görüldüğü, üzere sıcaklık ve basınç dağılımına bağlı olarak her bir modül ve kısımda farklı malzemeler kullanılması zorunluluğu ortaya çıkmaktadır.

Ti-Al alaşımları motorun kompresör kısmının düşük basınç bölgesinde yer almaktadır. Bu çalışmada üretilen paleler Ti-Al alaşımlarının havacılık ve medikalde en yaygın kullanılanı olan Ti6A14V malzemesidir. Söz konusu alaşım yüksek mukavemet değeri, görece hafif olması, üstün korozyon direncine sahip olması gibi özellikleri nedeniyle gaz türbin motorlarında kullanım için oldukça uygundur [10,11]. Talaşlı

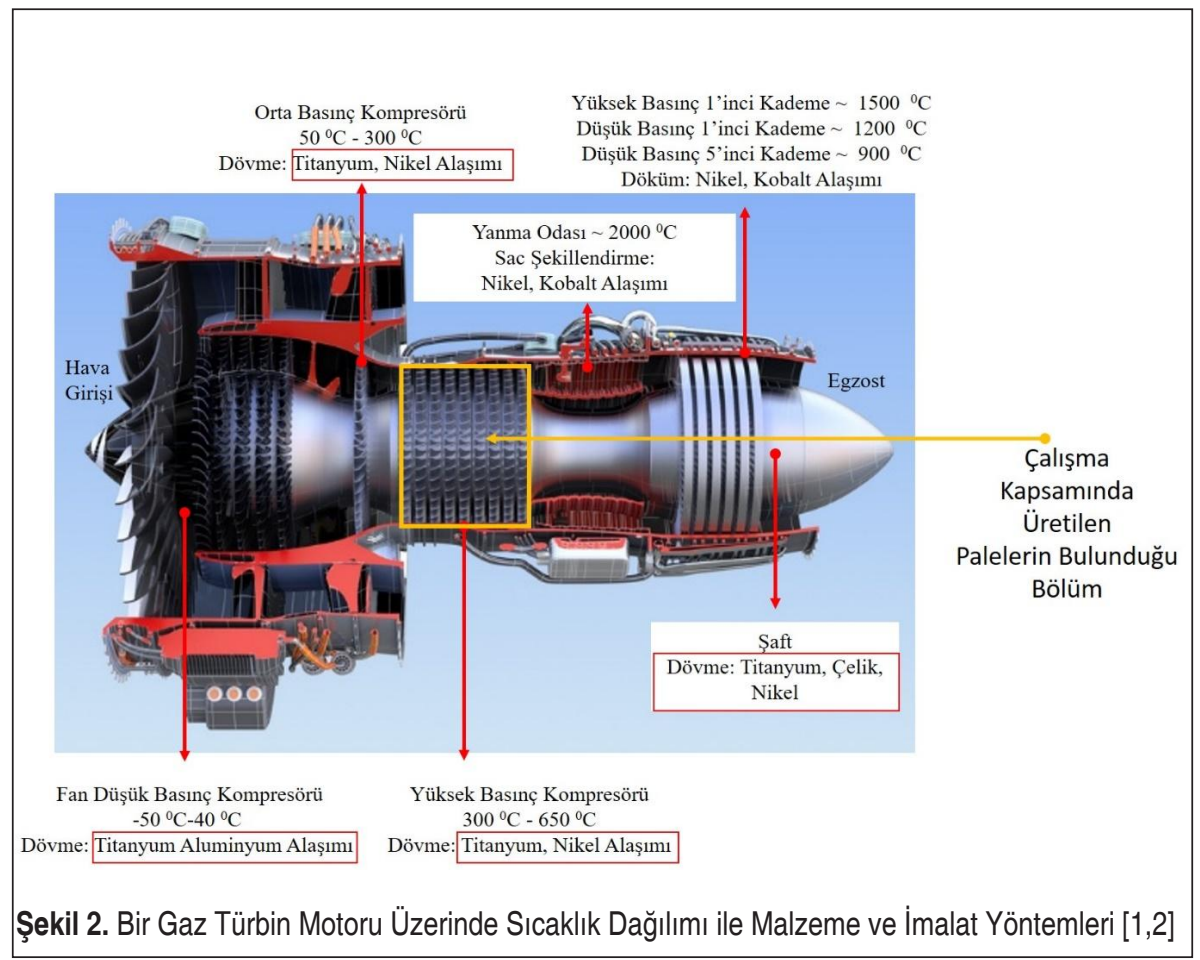


imalat gibi geleneksel yöntemlerle, karmaşık şekilli Ti6Al4V malzemelerini işlemek, termal iletkenliğinin düşük olması, yüksek sertliğe sahip olması, yüksek kimyasal reaksiyon özelliği ve aynı zamanda da atık olarak geriye kalan talaşların maliyetinin yüksek olması nedeniyle verimli değildir $[12,13]$. Bu nedenle bu çalışmada EÜ yöntemi ile üretim tercih edilmiştir.

Yapılan literatür çalışmalarında; EÜ ile Ti6Al4V ile jet motorlarındaki kompresör çark1 (impeller) ve pale gibi parçaların üretim süreçlerinin olgunlaştığ1 gözlemlenmektedir. [14,15]. Ti6Al4V alaşımı ile yapılan üretimler medikal alanda da yaygınlaşma süreci içerisindedir $[16,17,18]$. Diğer taraftan pale gibi karmaşık şekilli parçaların Ti6Al4V malzeme ile üretimi ve geometrik doğrulamasına yönelik yapılan literatür taramasında Tel Erozyon (Wire Electric Discharge Machine-WEDM) ile yapılan bir çalışma karşımıza çıkmaktadır. Yapılan çalışmada dışbükey (Konveks) yüzeylerde 8 $\mu$, içbükey yüzeylerde ise $6 \mu$ yüzey hassasiyeti ile parça üretilmesi söz konusudur. Diğer taraftan, boyutsal doğrulama açısından hareketli telin üçüncü boyutta hareket ettirilmesi güç olduğundan, WEDM teknolojisinin dikey eksende değişim gösteren yüzey profillerinde kullanılması mümkün olmadığı gözlemlenmiştir [19]. Bir başka çalışmada, Directed Energy Deposition (DED-Direkt enerji biriktirme) yöntemi ile Ti6Al4V alaşım kullanılarak silindir geometriye sahip bir deney parçası üretilmiştir. Yapılan çalışma sonucunda yüzey hassasiyetinin $\pm 2,5 \mathrm{~mm}$ tolerans değerinde olduğu görülmüştür [20]. Bu durumun sebebinin DED prosesinin tel ergitmeye dayalı çalışma yönteminden kaynaklandığı değerlendirilmektedir. Bu nedenle WEDM ve EÜ yöntemlerinden DED metodu gibi teknolojilerin pale benzeri karmaşı yüzeye sahip parçalarda kullanılmayacağı değerlendirilmektedir. EÜ ile Ti6A14V malzemelerin geometrik doğrulamasına yönelik yapılan çalışmalar genel olarak artık gerilmelere (residual stress) bağlı çarpıklık ve yüzey deformasyonlarını önlemeye yönelik çalışmalardır. Bununla beraber EÜ ile Ti6Al4V parçalardaki boyutsal değişimlerin incelendiği çalışmalarda kullanılan parçaların ya küp şekline sahip basit formda ya da ince duvarlı parçalar olduğu gözlemlenmektedir [21].

Bu çalışmada ise literatürde karşılaşılan araştırmalardan farklı olarak gaz türbinli motorun kompresör bölgesinde kullanılan paleler örnek alınarak Ti6A14V alaşımı ile EÜ yöntemi üretilmiş ve geometrik doğrulama çalışmaları yapılmıştır.

\section{MATERYAL VE YÖNTEM}

\subsection{Havacılık Endüstrisinde EÜ Uygulamaları}

Daha önceden bahsedildiği üzere EÜ ile üretim sadece havacıllk sektöründe değil; medikal, uzay ve otomotiv gibi diğer sektörlerde de hızla yer edinmektedir. 1980'li yıllarda ilk patent çalışmaları yapılan EÜ teknolojileri ile yapılan üretimlerin yıllar içinde pazar payını artırdığ 1 gözlemlenmektedir. Bu kapsamda, Wohlers Associates ta- 


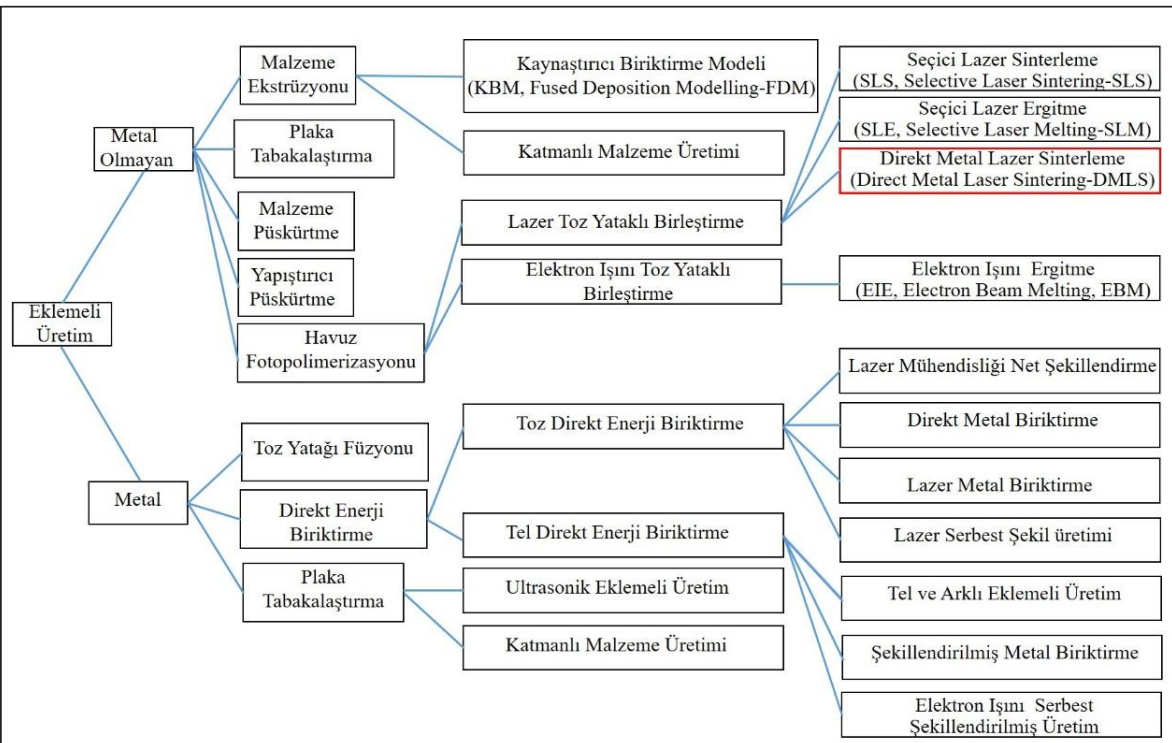

Şekil 3. EÜ Teknolojilerinin Türleri [24]

rafından yayımlanan yıllık EÜ dünya pazarı raporuna göre; EÜ’nün pazar payı 2012 yılında 2,25 Milyar ABD Doları, 2016 yılında 6 Milyar ABD Doları iken 2020 yılında 21 Milyar ABD Doları seviyesine çıkacağı öngörülmüştür [22]. Bu hızlı büyümenin, EÜ’nün geleneksel üretim yöntemlerinin yerini alabilecek tümden değişimci bir yöntem olmasından kaynaklandığı değerlendirilmektedir [23]. EÜ teknolojilerinin kendi içinde birçok farklı türü mevcuttur. Şekil 3'te EÜ teknolojilerinin türleri sunulmaktadır. Sahadaki uygulamalara bağlı olarak, her bir EÜ teknolojisinin kendine özgü avantaj ve dezavantajları mevcuttur. Bu makaleye konu olan kompresör palesinin üretimi, havacılık alanında yaygın kullanıma sahip olan DMLS yöntemi ile gerçekleştirilmiştir.

Talaşıı üretime kıyasla atık miktarının az olması, EÜ teknolojilerinin hava araçları ve hava araçları motorlarında kullanımının avantajlarından bir tanesidir. Uçak motorlarında kullanılan malzemelerin genellikle maliyeti yüksektir. Bu nedenle atık miktarının az olması oldukça önemlidir [25]. "Ham Malzeme" / "Uçağa Takılmaya Hazır Ürün Ağırlığgı” (Buy-to-Fly-Ratio) oranının düşük olmasından dolayı, EÜ’nün uçak motor parçalarında kullanımının daha da yaygınlaşacağı öngörülmektedir [26,27]. Malzeme tasarrufu ve ağırlık azaltmanın yanı sıra hava yolu işletmecilerinin, uçak motorlarında aradığg en önemli özelliklerin güvenlik ve verimlilik olduğu bilinmektedir. EÜ, son ürünün kalitesini olumlu açıdan etkileyebilen tekli veya çoklu malzeme kullanımları, 1sı, basınç gibi birçok değişkenin kontrol edilebilmesine olanak sağlaması nedeniyle güvenlik ve verimliliğe katkı sağladığı değerlendirilmektedir [28]. İlave olarak, EÜ teknolojileri, sadece üretim aşamasında değil Bakım, Onarım ve 
Yenileme (BOY, Maintenance, Repair and Overhaul-MRO) aşamasında da geniş bir kullanım alanına sahiptir [29]. Bir hava aracının ömür devri boyunca ortaya çıkan maliyetin \%20-40 arası tedarik ve \%60-80 arası BOY faaliyetlerine harcandığı göz önüne alındığında [7,30] EÜ teknolojilerinin havacılık endüstrisinde kullanımının hem üretim hem de devam eden destek (Follow-on-Support) fazında maliyet etkin bir çözüm sunduğu ortaya çıkmaktadır.

\subsection{Havacılık Endüstrisinde Ti6Al4V Uygulamaları}

Ti6Al4V alaşımı, ilk olarak, 1950'li yıllarda uçak yapısal parça uygulamaları için üretilmiştir. ASTM F1472 [31] ve ASTM 2924 [32] standartlarına göre Ti6Al4V alaŞımı malzeme kompozisyonu, \%90 Ti, \%5.48 Al, \%4.22\% V, \%0.369 C, \%0.112 Fe, $\% 0.0625 \mathrm{Sn}, \% 0.00386 \mathrm{Nb}, \% 0,0099 \mathrm{Cr}$ olarak belirlenmektedir. Üretimde kullanılacak olan tozun içeriğine yönelik, üreticiden alınan Uygunluk Sertifikası (Certificate of Conformance-CoC) ile bahsi geçen standartlarda yer alan verilerin birbiri ile örtüştüğü doğrulanmıştır. Ti6Al4V alaşımın yoğunluğu $4,3 \mathrm{gr} / \mathrm{cm}^{3}$ olarak bilinmektedir. Düşük yoğunluk, yüksek mekanik dayanım, yüksek korozyon direnci ve bio-uyumluluk özelliği Ti6Al4V alaşımını oldukça cazip kılmaktadır [33,34].

\subsection{Direkt Metal Lazer Sinterleme (DMLS)}

EÜ yöntemlerinden olan DMLS metodu, bir toz yatağı içerisine serilen tozların lazer 1şını ile sinterlenmesi prensibine dayanmaktadır. Her bir toz taneciği üzerine lazerin çarpma süresi 0,5-25 milisaniyedir. Bu zaman zarfında, tozlar kısmen ergiyip soğutularak, istenilen parçayı meydana getirmek üzere katmanlar halinde birbirine bağlanmaktadır [35]. Yüksek soğuma hızından dolayı, EÜ ile imal edilen parçaların çekme özellikleri ve sertliklerinin, talaşlı imalat ya da döküm yöntemi ile üretilmiş malzemelere göre daha yüksek olduğu gözlemlenmektedir [36]. Diğer taraftan, EÜ ile üretilen parçaların yüzey pürüzlülüğü geleneksel yöntemlere kıyasla daha yüksektir. Söz konusu yüksek yüzey pürüzlülüğü, gerilim yoğunlaşmasının artmasına ve dolayısıyla parçanın yorulma etkisine daha erken maruz kalmasına yol açmaktadır. İlave olarak, parçada meydana gelen gözeneklilik ve katmanlar arasındaki yetersiz birleşme, yorulmayı daha öne çekebilmektedir. Bu nedenle, üretimden sonra, Sıcak İzostatik Presleme (SİP, Hot Isostatic Press-HIP) ile parçanın yoğunluğunda artış sağlanması sayesinde yorulma mukavemetinin yükseltilmesi sağlanmaktadır [37]. DMLS ile üretilen Ti6Al4V parçalarının maksimum çekme kuvvetlerinin belirlenmesine yönelik yapılan çalışmada, hiç ısıl işlem yapılmamış numunede $1150 \mathrm{Mpa}$ olan maksimum çekme kuvveti, gerilim giderme 1 sıl işlemi sonrasında $1230 \mathrm{Mpa}$ olarak belirlenmiştir. HIP işlemi sonrasında ise $960 \mathrm{Mpa}$ olarak belirlenmiştir [38]. Bu çalışmada 1sıl işlem uygulamas $800{ }^{\circ} \mathrm{C}$ gerçekleşmiş olup söz konusu değer, toz üreticisi firma tarafından sağlanan bir referans değerdir. EÜ yöntemi ile Ti6A14V alaşımı kullanılarak üretilen parçaların geometrisi ve mekanik özellikleri üzerinde birçok faktörün yer aldığı bilin- 
mektedir. Kompresör palesinin EÜ yöntemi ile üretiminde, imalat kalitesini etkileyen ve değiştirilebilir faktörler aşağıda yer almaktadır:

- Katman kalınlığı,

- Lazer gücü,

- Tarama hizi,

- Tarama deseni,

- İnşa yönü,

- Yanal kayma aralığı.

\subsubsection{Katman Kalınlı̆̆ı}

EÜ üretim yönteminin çalışma sistematiği eşit aralıklara sahip katmanların üst üste getirilmesidir. Özellikle iç ve dış yüzeylerinde karmaşık bileşenler için alternatif bir çözüm ortaya koyan, ideal birleştirme malzemesi aracılığıyla katmanlar halinde imal edilmesini sağlayan gelişmiş bir üretim tekniğidir [35-37,39]. Katman kalınlığı limitler dâhilinde azaltılabilir ancak daha ince katman kalınlıklarının daha ince olması parçanın üretim süresini uzatmakta ve dolayısıyla parça maliyetini artırmaktadır [40]. Diğer bir ifade ile katman kalınlıklarının arttırılması üretim zamanının ve sonuçta üretim maliyetinin azaltılmasını sağlamaktadır. Ancak katmanlar kalınlaştıkça, basamak etkisinden (stair step) dolayı pozitif bir korelasyon içerisinde yüzey pürüzlülüğü de artmaktadır [41]. İlave olarak, katman kalınlığı arttıkça parça içerisindeki ergimemiş toz partikülleri ve gözenek boşlukları gibi süreksizlikler de ortaya çıkmaktadır [42]. Söz konusu süreksizlikler, parçanın yoğunluğunun azalmasına neden olmaktadır. Düşük yoğunluk ise parçanın başta akma dayanımı olmak üzere mekanik özelliklerinde düşüşe sebep olmaktadır [43]. Yoğunluk azalmasının bir başka sonucu da sertliğin azalması olarak ortaya çıkmaktadır. Genel değerlendirmede, katman kalınlığının tarama hızı ve lazer gücü ile bir optimizasyon içerisinde olması gerekliliği ortaya çıkmaktadır. Aksi takdirde, ergimemiş toz partikülleri ve gözenek boşluklarından kaynaklanan süreksizlikler, yoğunluk azalması ve akma dayanımının düşmesi gibi olumsuz sonuçları ortaya çıkarmaktadır. Süreksizliklerin bertaraf edilmesi amacıyla yapılan çalışmalarda, azaltmanın birim hacimdeki enerji yoğunluğu ile bağıntılı olduğu ve yeterince enerji sağlandığında tam ergimenin meydana geldiği, dolayısıyla boşlukların oluşmadığı belirlenmektedir [44].

\subsubsection{Lazer Gücü}

EÜ yöntemlerinden biri olan DMLS, temelde toz partiküllerinin lazer gücü ile ergitilmesi prensibine dayanmaktadır. Burada enerji yoğunluğu önemli bir parametredir. Enerji yoğunluğu, lazer gücünün (P), katman kalınlığı (t), tarama hızı (V) ve Yanal Kayma Aralığı (Hatch Space-HS) çarpımına oranı olarak belirlenmektedir [44].

Eşitlik (1)'de verilen, “Andrew Sayısı” ampirik eşitlik olarak enerji yoğunluğunu ifade etmektedir. 


$$
A_{N}=\frac{P}{H s \times v}
$$

Bu bağıntıya göre enerji yoğunluğu, lazer gücü arttıkça artmakta, tarama mesafesi ve tarama hızı azaldıkça azalmaktadır. Şekil 4'te gösterildiği üzere lazer gücüne bağlı olarak, lazer 1şıı tarafından taşınan enerji daha önceden sinterlenmiş kısımla, yeni tozu bir araya getirmektedir. Bu sayede, katmanların yanal düzlemde birbirlerine bağlanması (bonding) işlemi gerçekleşmektedir.

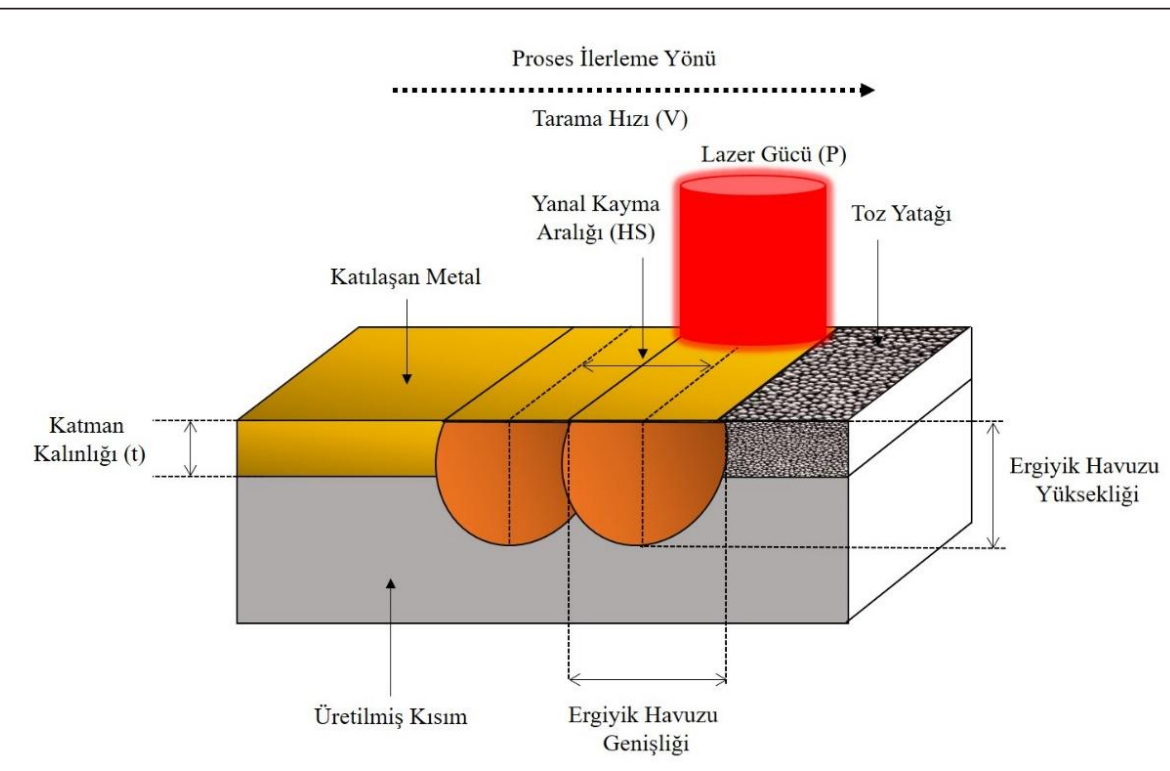

Şekil 4. Lazer Sinterlemede Proses Illerleme Yönüne Bağlı Olarak Katman Kalınlığı Oluşumu [45]

Yüzey hassasiyetinin ilerleme hızı, katman kalınlığı ve lazer gücünün kontrolü ile sağlandığı bilinmektedir [46]. Palelerin üretildiği EOSM290 DMLS (EOS GmbH, Almanya) makinesinin azami lazer gücü 400 Watt’tır. Lazer gücünün az, ilerleme h1zının yüksek olduğu durumlarda ergime tam oluşmamakta ve bu durumda yapı içerisinde süreksizliklerin oluşması ve var olanların artması, ilave olarak yüzey hatalarının çoğalması durumu söz konusu olmaktadır [47]. Diğer taraftan, yüksek lazer gücü ve düşük ilerleme hızında anahtar deliği (keyhole) şeklinde gözenek oluşumu söz konusu olmaktadır [48].

\subsubsection{Tarama Hizı}

Tarama hızı, eş zamanlı ergitilen toz partiküllerinin miktarını belirleyen bir değer olarak tanımlanabilmektedir [49]. Tarama hızı, enerji yoğunluğu parametresi içerisinde 
oldukça önemli bir faktördür. Daha önce bahsedildiği üzere lazer enerji yoğunluğu, bir katmanın taranması sırasında malzemenin hacmi başına uygulanan ortalama enerjinin bir ölçüsüdür. Lazer enerji yoğunluğu, enerji girişini ölçen ve parçanın yüzey kalitesini etkileyen önemli bir faktördür. Artırılmış bir lazer gücü, daha yüksek hızlarda ergime oluşmasına ve isı penetrasyonunun daha derine ulaşmasına olanak sağlamaktadır. Tarama hızının artırılması, ısının yükselmesi için ihtiyaç duyulan zamanın kısalması, ergiyik havuzunun daralması ve Isı Etkisi Altında Kalan Bölge (ITAB)'nin küçülmesine yol açmaktadır [50]. Sonuç itibariyle tarama hızının artırılması yoğunluğun azalmasına sebebiyet vermektedir. Tarama hızı ve lazer gücü arasında istenilen mekanik özellikler ve yüzey hassasiyetine yönelik parametreleri değiştirerek bir optimum noktanın bulunması gerekmektedir [51].

\subsubsection{Tarama Deseni}

Tarama deseni, lazer ışınının katman üzerinde ilerleme şeklini ifade etmektedir. Farklı tarama desenleri, parçaların geometrik ve mekanik özellikleri üzerinde etki meydana getirmektedir. Şekil 5'te görüldüğü üzere farklı tarama desenleri mevcuttur. Tarama modelinin uygun seçilmesi artık gerilmelerin (Residual Stress) ve termal etkiden kaynaklanan herhangi bir bozulmanın meydana gelme olasılığını azaltmaktadır. Yüzey deformasyonu ve süreksizlik açısından, Şekil 5.a.'da yer alan fraktal tarama deseni, en düşük yüzey deformasyonu ve süreksizlik oluşturan modeldir. Aynı değerlendirme

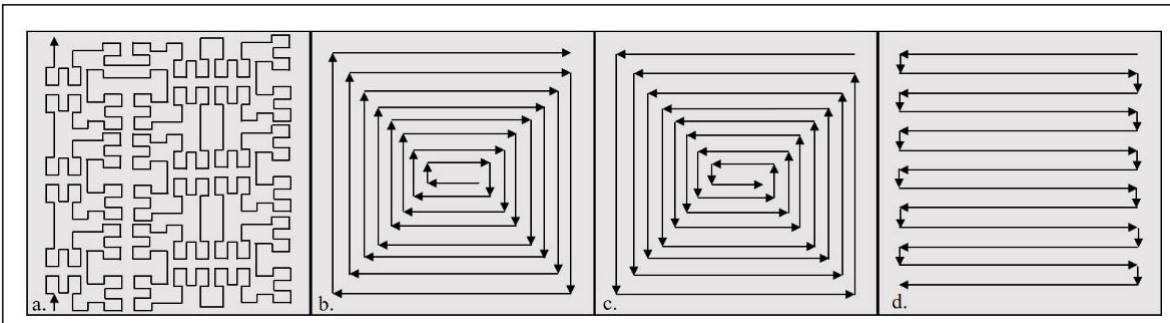

Şekil 5. Tarama Desenleri a. Fraktal, b. Dışa Doğru Ilerleme, c. İçe Doğru Ilerleme, d. Zikzak [52]

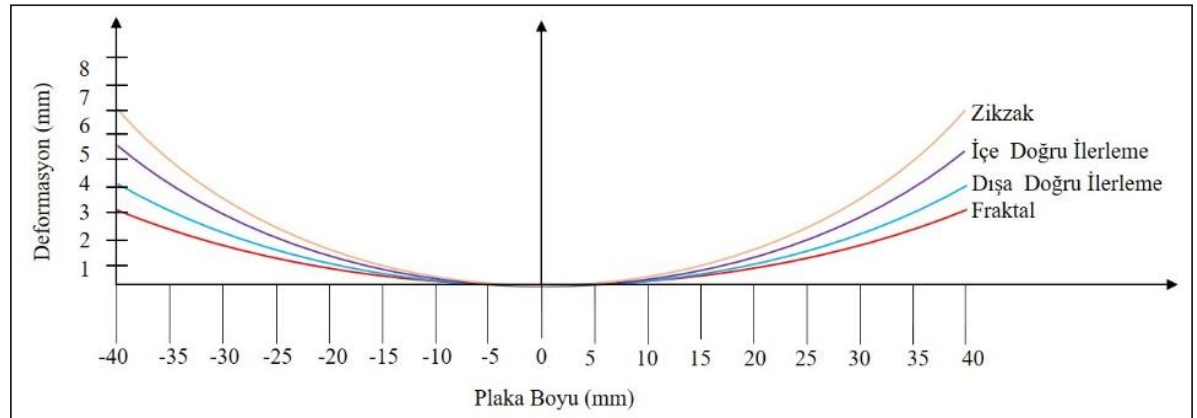

Şekil 6. Tarama Desenlerine Bağlı Olarak Oluşan Yüzey Deformasyonları (çarpıklıklar) [53] 
çerçevesinde, Şekil 5.b.'de yer alan dişa doğru ilerleme (Off-Set Out) deseni ikinci sırada, Şekil 5.c.'de yer alan içe doğru ilerleme (Off-Set In) deseni üçüncü sırada ve Şekil 5.d.'de yer alan zikzak deseni ise dördüncü sırada yer almaktadır.

Şekil 6'da tarama desenlerine bağlı olarak dış düzlem distorsiyonları (deformasyonları) görülmektedir. Burada "0" noktası plakanın orta noktasını ifade etmekte olup, bu noktadan pozitif ve negatif yöne doğru distorsiyonların olduğu görülmektedir.

\subsection{5 İnşa Yönü}

İnşa yönü, parçanın uzunlamasına ekseni ile dikey eksen arasındaki dar açıdır. Parçanın inşa yönü, aynı katman üzerinde farklı soğuma oranları oluşturacağı için parçanın mikro yapısı ve mekanik özelliklerini etkileyen bir faktördür. Dikey inşa yönünde daha iyi dayanım ve uzama değerleri elde edilmektedir. Genel olarak, dikey inşa yönünde daha iyi dayanım ve uzama değerleri elde edilmektedir [42, 54]. Şekil 7'de bu makaleye konu olan kompresör palelerinin inşa yönü görülmektedir.

\subsubsection{Yanal Kayma Aralı̆̆}

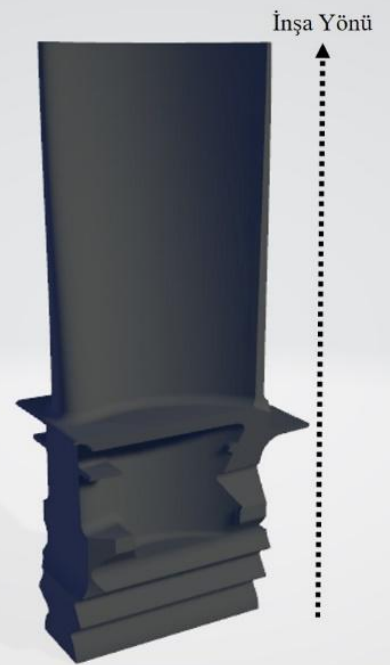

Şekil 7. Kompresör Palelerinin İnşa Yönü

Yanal kayma aralığı, iki komşu tarama çizgisi arasındaki mesafe olarak tanımlanmaktadır. Diğer bir ifade ile katmanlar inşa edilirken, tarama desenleri arasındaki geçiş mesafesidir. Şekil 8'de görüldüğü üzere her iki çizgi arasındaki mesafedir. Üretim

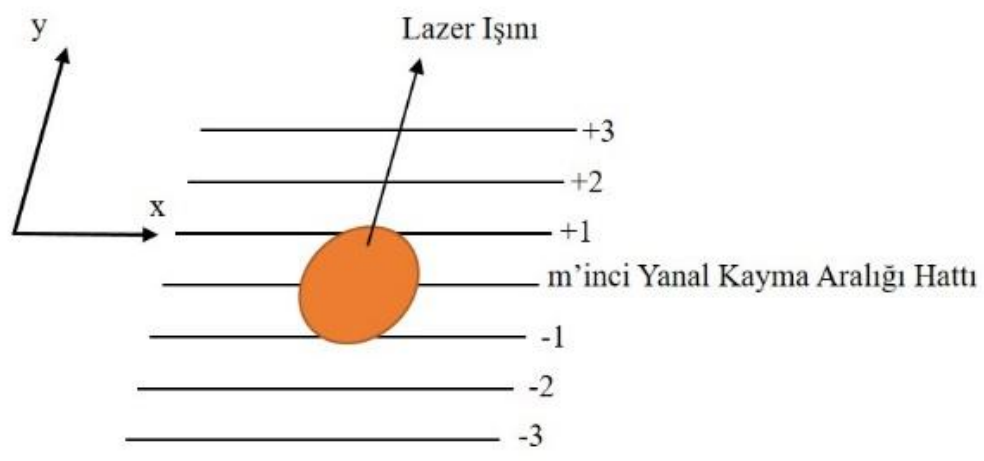

Şekil 8. Yanal Kayma Çizgileri ve Yanal Kayma Aralığı [51] 


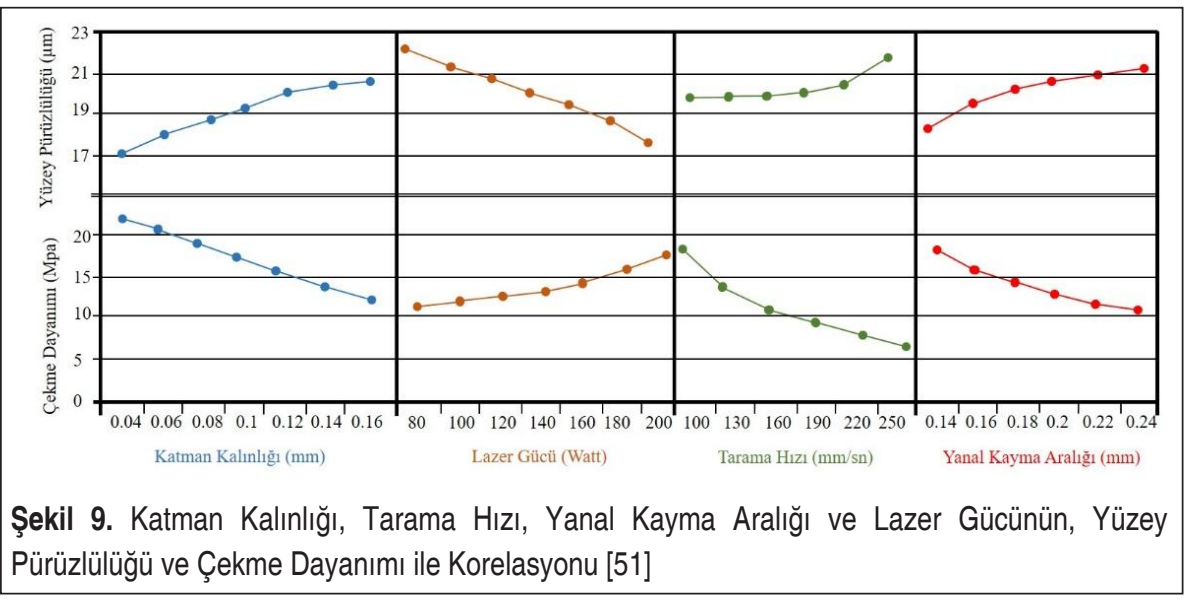

geometrisi içerisinde lazer ışını x ekseni üzerinde ilerlemekte, yanal kayma aralığı kadar y eksenine geçmekte ve yeniden x ekseninde rotası boyunca ilerlemektedir.

Bu mesafe, lazer 1şınlarının üst üste geldiklerinde lazer gücüne bağlı olarak enerji dağılımı ve dolayısıyla sürekli sinterleme yapılan bölgenin oluşumda etkili olmaktadır.

Genel değerlendirmede; Şekil 9'da görüldüğü üzere yüzey pürüzlülüğü katman kalınlığı, tarama hızı ve yanal kayma aralığı ile pozitif korelasyon; lazer gücü ile negatif korelasyon içerisindedir. Benzer bir kıyaslama çekme dayanımı için de yapılmıştır. Çekme dayanımı katman kalınlığı, tarama hızı ve yanal kayma aralığı ile negatif korelasyon; lazer gücü ile pozitif korelasyon içerisindedir.

\section{KOMPRESÖR PALELERINIIN ÜRETIM SÜRECİ}

Şekil 10'da üretim ve test sürecinin akış şeması sunulmaktadır. Söz konusu şemada üretime yönelik toz ve tezgâh parametreleri, üretimin gerçekleşeceği birim ve bağımsız test biriminde gerçekleşmesine yönelik iş adımları yer almaktadır.

Şekil 11'de, EÜ-DMLS yöntemi ile Ti6A14V toz kullanarak EOSM290 tezgâhında üretimi gerçekleştirilen palelerin, Catia (Dassault Systèmes, Fransa) bilgisayar destekli tasarım yazılımı ile üretilen katı model görülmektedir. Söz konusu katı modelin üretiminde, halen gaz türbin motorlarının kompresör bölgesinde kullanılan palelerin boyutsal ölçüleri esas alınmıştır.

Üretim parametreleri olarak katman kalınlığ $60 \mu$, lazer gücü 200 Watt ve hacimsel enerji yoğunluğu $9 \mathrm{~mm} 3 / \mathrm{sn}$ değerleri kullanılmıştır. Tarama deseni olarak dişa doğru ilerleme parametresinin kullanıldığı gözlemlenmiştir. Yaklaşık 7,5 saat süren üretimden sonra Şekil 12'de görüldüğü üzere, ön ölçümler ve gözle kontrol (visual inspection) gerçekleştirilmiştir. 


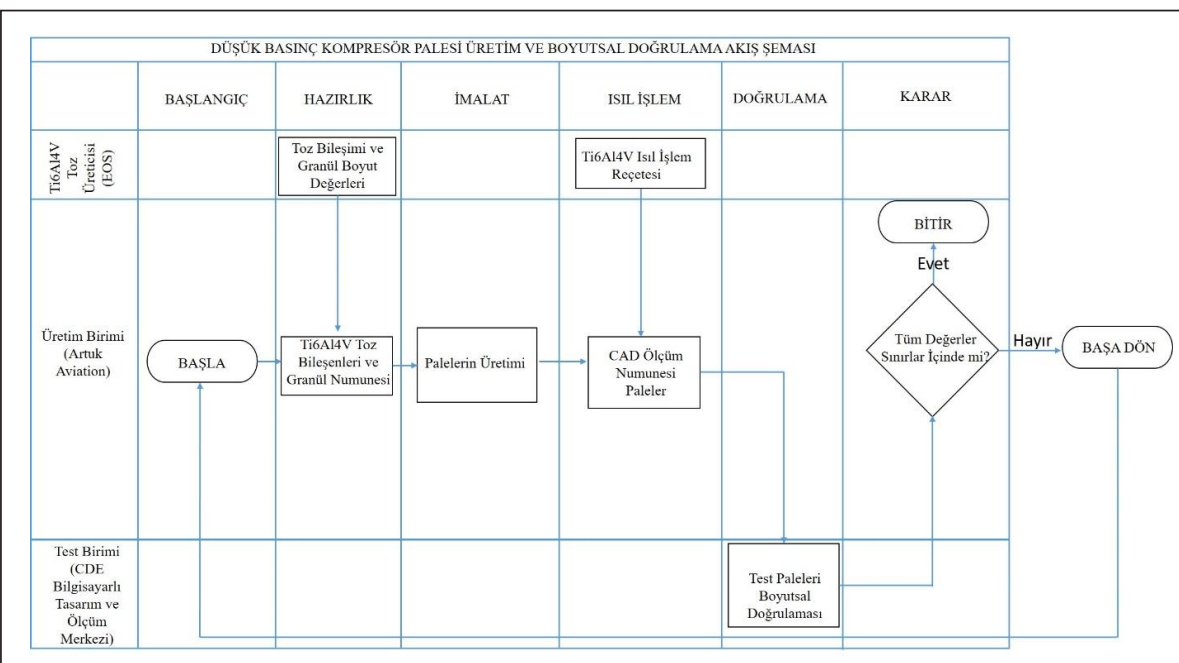

Şekil 10. Kompresör Palesi Üretim ve Test Aşamaları Akış Şeması

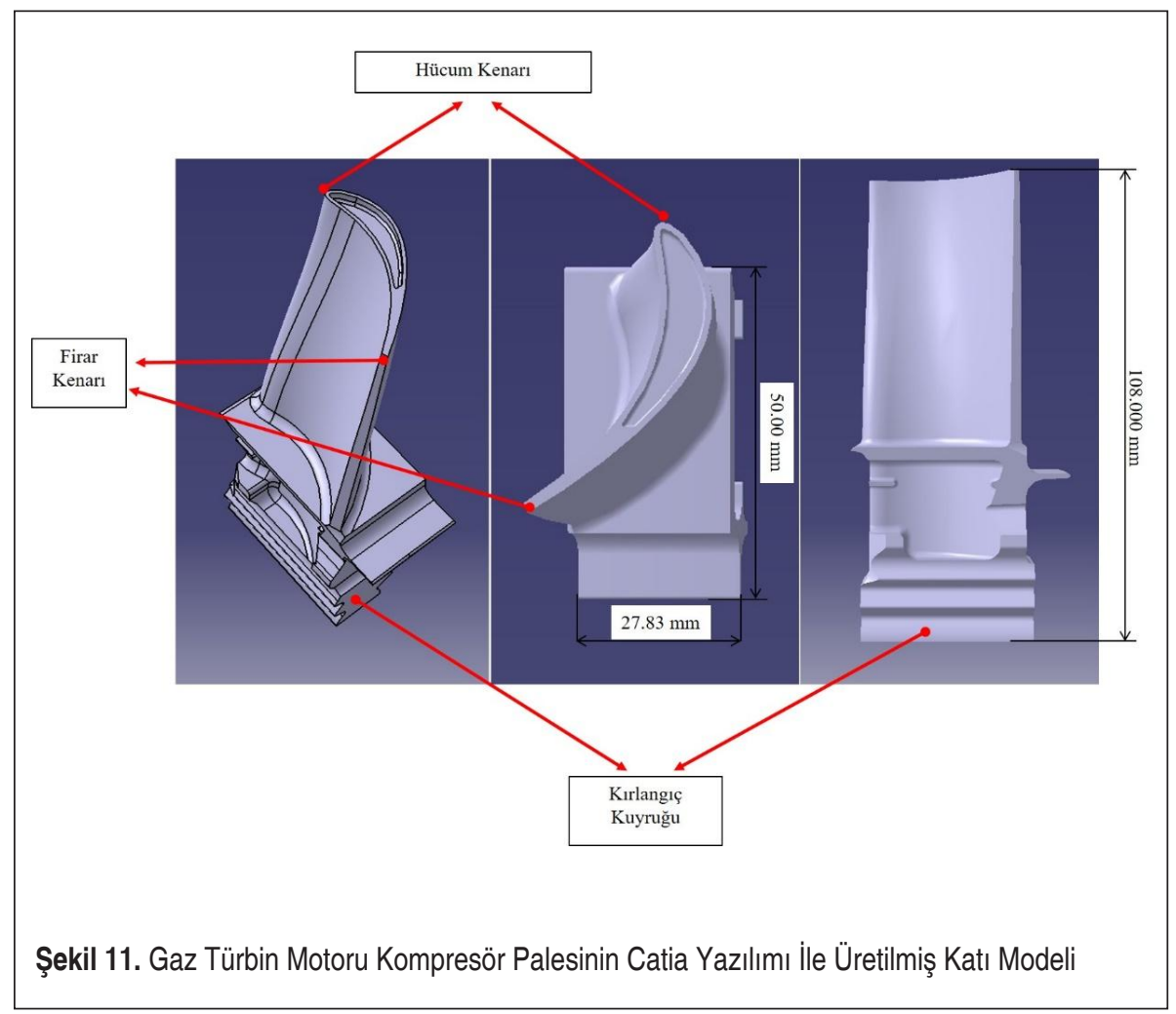




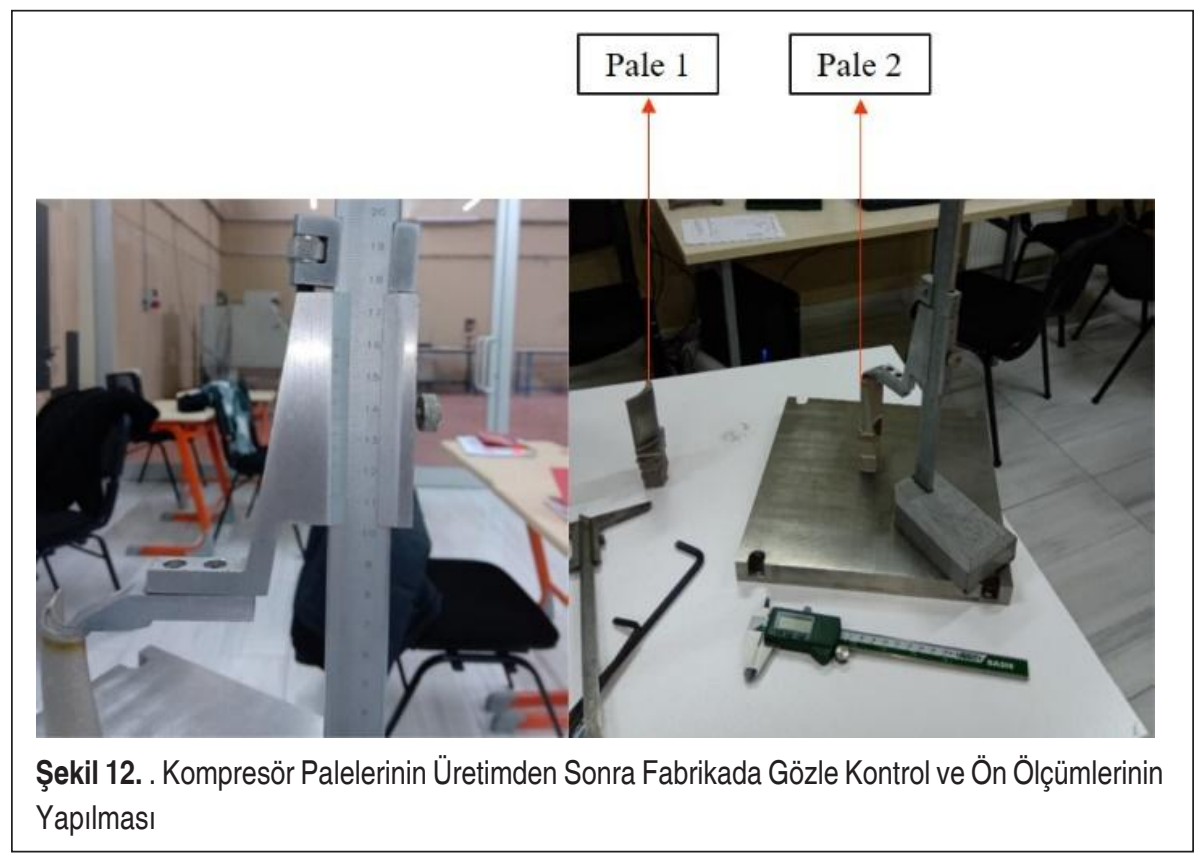

Ön ölçümlerin olumlu sonuç vermesinin ardından, ssıl işlem yapılması safhasına geçilmiştir. Üretici firmadan, Ti6Al4V alaşımının sinterleme sonrasında yapısında ardılişlem olarak alınan öneriler ve yapılan kaynak taramaları $[55,56,57]$ sonucunda firın kontrol panelinden, 2 saat içinde oda sıcaklığından $\left(22 \pm 2{ }^{\circ} \mathrm{C}\right), 800^{\circ} \mathrm{C}$ 'ye kadar, 2 saat $800{ }^{\circ} \mathrm{C}$ 'de tutulması ve ardından da aynı seyir ile soğutulması sağlanmıştır. Proses sırasında, firın haznesinde argon gazı kullanılmıştır.

\section{BULGULAR VE TARTIŞMA}

\subsection{Boyutsal Doğrulamaya Yönelik Fotogrametrik Tabanlı Veri Seti Elde Etme Yöntemi}

Üretim safhasının tamamlanmasının ardından, bu analiz çalışmasının odağında bulunan boyutsal doğrulama aşamasına geçilmiştir. Söz konusu doğrulama işlemi için, $1 \mu$ hassasiyetle ölçüm yapabilen Breuckmann Smartscan3D (Breuckmann GmbH, Almanya) tezgahı kullanılmıştır. Kamera ile yapılan ölçüm öncesinde, palelerin yüzeylerindeki parmak izi gibi kalıntıların arındırılması amacıyla kimyasal temizleme işlemi yapılmıştır. Şekil 13 ’te görüldüğü üzere, paleler sırayla geometrik doğrulama işlemi için bir döner tabla üzerine yerleştirilmiştir.

Söz konusu ölçüm tezgâhının çalışma prensibi EÜ için üretilen 3 boyutlu katı model ile üretilmiş olan parçanın geometrik kıyaslamasının yapılması esasına dayanmakta- 


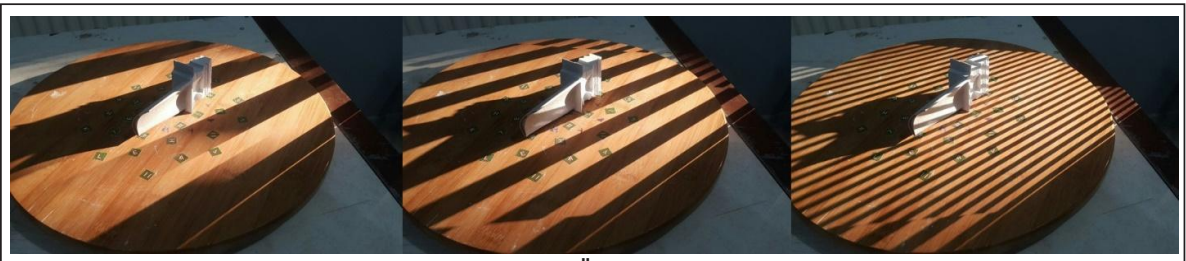

Şekil 13. Kompresör Palelerinin Smartscan 3D Ölçüm Cihazında Geometrik Doğrulama Verilerinin Alınması

Tablo 1. Fotogrametrik Analizlere Yönelik Elde Edilen Veriler

\begin{tabular}{|c|c|c|c|c|c|c|c|c|}
\hline$\#$ & $\begin{array}{c}1 \text { Nu'lı } \\
\text { Pale } \\
\text { Basınç } \\
\text { Yüzü }\end{array}$ & $\begin{array}{c}2 \text { Nu'lı } \\
\text { Pale } \\
\text { Basınç } \\
\text { Yüzü }\end{array}$ & $\begin{array}{c}1 \text { Nư'ı Pale } \\
\text { Basınç } \\
\text { Yüzü } \\
\text { Kırlangıç } \\
\text { Kuyruğu } \\
\text { Bölgesi }\end{array}$ & $\begin{array}{c}\text { 2 Nu'lı Pale } \\
\text { Basınç Yüzü } \\
\text { Kırlangıç } \\
\text { Kuyruğu } \\
\text { Bölgesi }\end{array}$ & $\begin{array}{c}\text { 1 Nu'lı } \\
\text { Pale } \\
\text { Emme } \\
\text { Yüzü }\end{array}$ & $\begin{array}{c}\text { 2 Nu'lı } \\
\text { Pale } \\
\text { Emme } \\
\text { Yüzü }\end{array}$ & $\begin{array}{c}\text { 1 Nu'lı Pale } \\
\text { Emme Yüzü } \\
\text { Kırlangıç } \\
\text { Kuyruğu } \\
\text { Bölgesi }\end{array}$ & $\begin{array}{c}2 \text { Nu’lı Pale } \\
\text { Emme } \\
\text { Yüzü } \\
\text { Kırlangıç } \\
\text { Kuyruğu } \\
\text { Bölgesi }\end{array}$ \\
\hline 1 & $-0,0627$ & $-0,0725$ & $-0,072$ & $-0,1117$ & 0,0435 & $-0,2204$ & $-0,0422$ & $-0,1141$ \\
\hline 2 & $-0,0682$ & $-0,0805$ & $-0,1511$ & $-0,1361$ & $-0,007$ & 0,0275 & $-0,053$ & $-0,1223$ \\
\hline 3 & 0,0201 & $-0,015$ & $-0,1525$ & $-0,134$ & $-0,1067$ & $-0,1273$ & 0,0284 & $-0,0053$ \\
\hline 4 & $-0,1697$ & $-0,1543$ & 0,2177 & 0,2177 & $-0,1172$ & $-0,1194$ & 0,0398 & 0,0276 \\
\hline 5 & 0,0041 & $-0,0399$ & 0,2397 & 0,3269 & $-0,1075$ & $-0,122$ & $-0,0272$ & $-0,0793$ \\
\hline 6 & $-0,1709$ & $-0,1549$ & $-0,1286$ & $-0,1136$ & $-0,1086$ & $-0,1122$ & $-0,1558$ & $-0,1775$ \\
\hline 7 & $-0,1392$ & $-0,1314$ & $-0,1032$ & $-0,1076$ & 0,1231 & 0,0335 & $-0,1354$ & $-0,1509$ \\
\hline 8 & $-0,0054$ & $-0,007$ & $-0,175$ & $-0,2005$ & $-0,1078$ & $-0,1882$ & $-0,0877$ & $-0,0995$ \\
\hline 9 & 0,153 & 0,1449 & 0,0288 & $-0,0075$ & $-0,1431$ & $-0,1553$ & 0,1818 & 0,0181 \\
\hline 10 & 0,2733 & 0,3124 & $-0,0865$ & $-0,1404$ & 0,0331 & 0,0537 & 0,1678 & $-0,0476$ \\
\hline 11 & $-0,1471$ & $-0,1725$ & $-0,0009$ & $-0,041$ & $-0,1644$ & $-0,1326$ & $-0,098$ & $-0,0624$ \\
\hline 12 & $-0,1465$ & $-0,2004$ & 0,0037 & $-0,0575$ & 0,1195 & 0,1235 & $-0,1081$ & $-0,0777$ \\
\hline 13 & 0,1188 & 0,115 & 0,0908 & 0,0492 & 0,0501 & 0,0323 & $-0,103$ & $-0,0725$ \\
\hline 14 & 0,1323 & 0,1042 & $-0,0157$ & $-0,0984$ & 0,0604 & 0,038 & $-0,1153$ & $-0,0949$ \\
\hline 15 & 0,0707 & 0,0621 & $-0,1582$ & $-0,1267$ & 0,0331 & 0,0522 & $-0,1169$ & $-0,0791$ \\
\hline 16 & 0,0415 & 0,0133 & $-0,1478$ & $-0,1627$ & 0,1058 & 0,0858 & $-0,104$ & $-0,0946$ \\
\hline 17 & 0,081 & 0,1051 & $-0,0772$ & $-0,1475$ & 0,1433 & 0,157 & $-0,0883$ & $-0,0879$ \\
\hline 18 & 0,0517 & 0,0705 & 0,3061 & 0,3308 & 0,1737 & 0,2197 & 0,636 & 0,1034 \\
\hline 19 & $-0,1567$ & $-0,1585$ & 0,2651 & 0,3133 & 0,2734 & 0,3017 & 0,2418 & 0,3094 \\
\hline 20 & $-0,1665$ & $-0,1464$ & $-0,0808$ & $-0,0984$ & $-0,057$ & $-0,0611$ & 0,1496 & 0,0439 \\
\hline 21 & $-0,0786$ & $-0,0978$ & & & $-0,0953$ & $-0,0971$ & 0,0797 & 0,0322 \\
\hline 22 & 0,1596 & 0,1466 & & & $-0,1276$ & $-0,0895$ & 0,0837 & 0,0293 \\
\hline 23 & 0,0029 & $-0,0092$ & & & & & & \\
\hline
\end{tabular}


dır. Benzer bir pale üzerinde yapılan boyutsal doğrulama çalışmasında basınç yüzeyinden 57, emme yüzeyinden 57 olmak üzere toplam 114 adet noktadan elde edilen verinin karar verme sürecinde yeterli mesnet sağladığı gözlemlenmiştir [21]. Bu çalışmada, Tablo 1'de görüldüğü üzere toplam 174 adet veriden oluşan bir doğrulama veri seti elde edilmiştir. Söz konusu veriler, palelerin basınç yüzü üzerinden 23 adet, basınç yüzü kırlangıç kuyruğu bölgesinden 20 adet, emme yüzü üzerinden 22 adet ve emme yüzü kırlangıç kuyruğu bölgesinden 22 adet olmak üzere her bir pale için toplam 87 noktadan gerçekleşmiştir. Mavi renkte olan değerler katı modele kıyasla negatif; turuncu renkli olanlar ise pozitif değişimleri göstermektedir. Toplamda 103 adet negatif değişim ve 71 adet pozitif değişim görülmektedir.

\subsection{Fotogrametrik Analiz Sonuçları}

Boyutsal doğrulama için 3 boyutlu katı model referans olarak kullanılmıştır. Ölçümler her iki pale için de aynı noktalardan yapılmıştır.

Smartscan3D ölçüm tezgâhında yapılan incelemeler sonucunda elde edilen veriler, palenin içbükey basınç yüzeyi (pressure surface) ve dışbükey emme yüzeyi (suction surface), verilerin gösterdiği değişime bağlı olarak renk skalasında büyüklük göstergesi olarak ifade edilmektedir.

Büyüklük göstergesi sütununda sarı ve kırmızı pozitif sapmayı (Expansion), mavi ise negatif sapmayı (Shrinkage) temsil etmektedir. Değişim ne kadar fazla olursa, renk o denli koyulaşmaktadır. İki palede yer alan renk dağılımının uyumu, üretim stratejisinin doğruluğu hakkında ipuçları vermektedir. Yeşil alanlar katı model ile palelerin ölçülerinin $\pm 0,05 \mathrm{~mm}$ limiti dâhilinde olduğunu gösteren yerlerdir. Şekil 14'te 1 . Nu'lı pale ve Şekil 15 'te 2 Nu'lı palelerin basınç yüzlerine ait fotogrametrik ölçümler sunulmuştur.

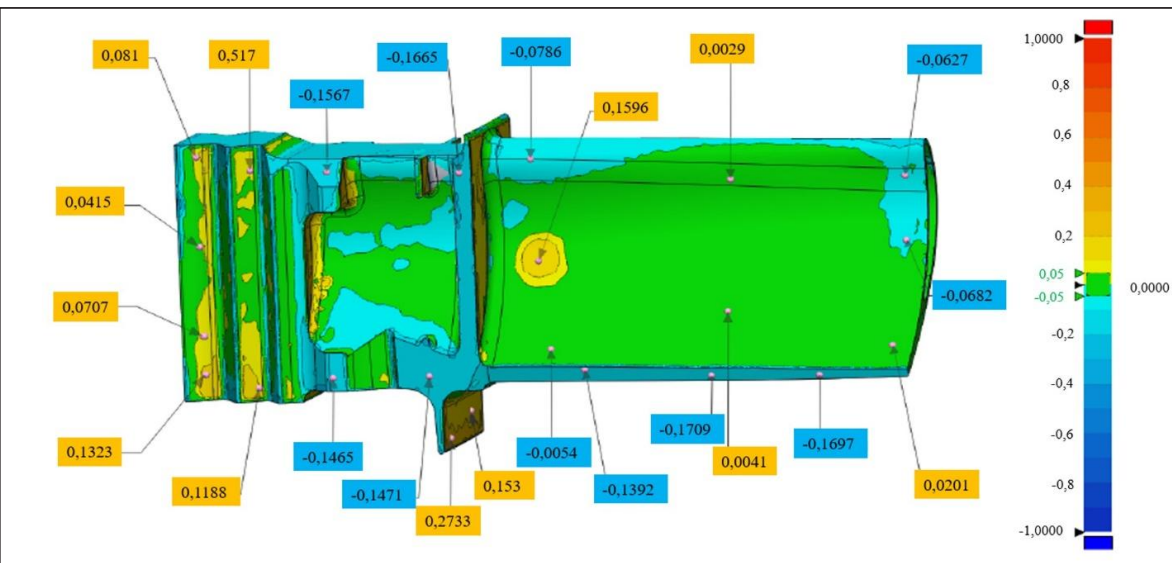

Şekil 14. 1 Nu’lı Pale Basınç Yüzü 


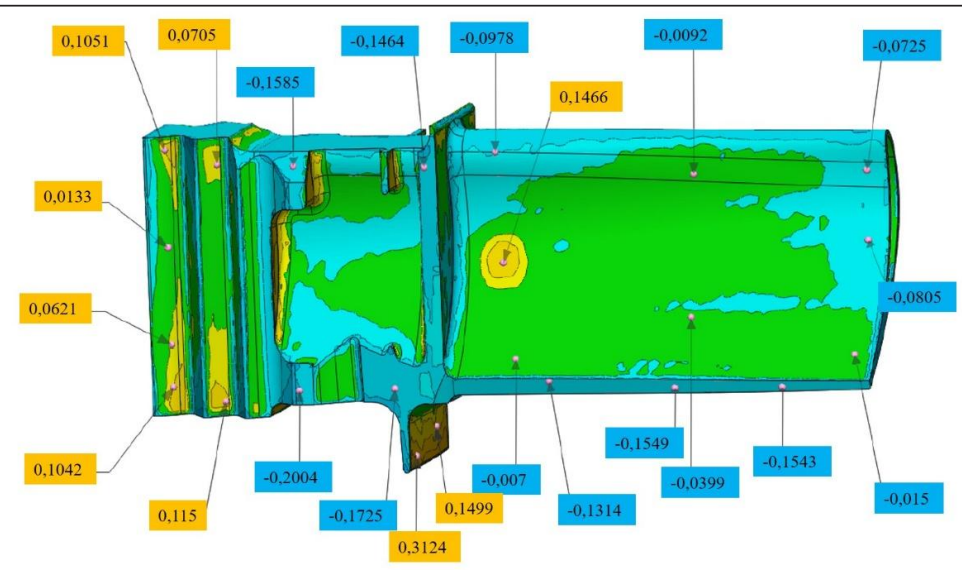

Şekil 15. 2 Nu’lı Pale Basınç Yüzü

Palelerin basınç yüzleri üzerinde gerçekleştirilen 46 adet ölçümden, 25 adet negatif değişimin ortalaması $0,11923 \mathrm{~mm}, 21$ adet ise pozitif değişimin ortalaması ise 0,103953 mm olarak gerçekleşmiştir. Şekil 16’ da yer alan kıyaslama grafiğinde görüldüğü üzere 1 ve 2 Nu'lı palelerin basınç yüzlerinin geometrik olarak birbirlerine çok yakın bir profile sahip olduğu görülmektedir. Yapılan hesaplama sonucunda her iki palenin basınç yüzünde gerçekleşen ortalama değişim $0,007117 \mathrm{~mm}(7,117 \mu)$ olarak belirlenmiştir.

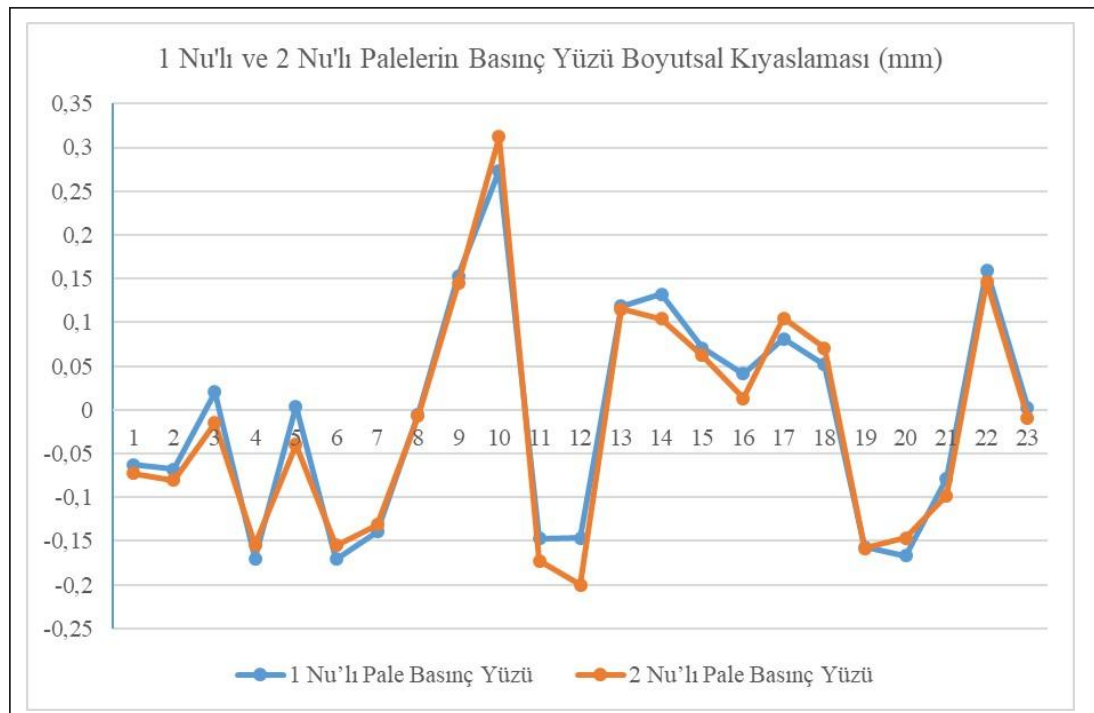

Şekil 16. 1 Nu’|ı ve 2 Nu’। Palelerin Basınç Yüzü Boyutsal Kıyaslaması 


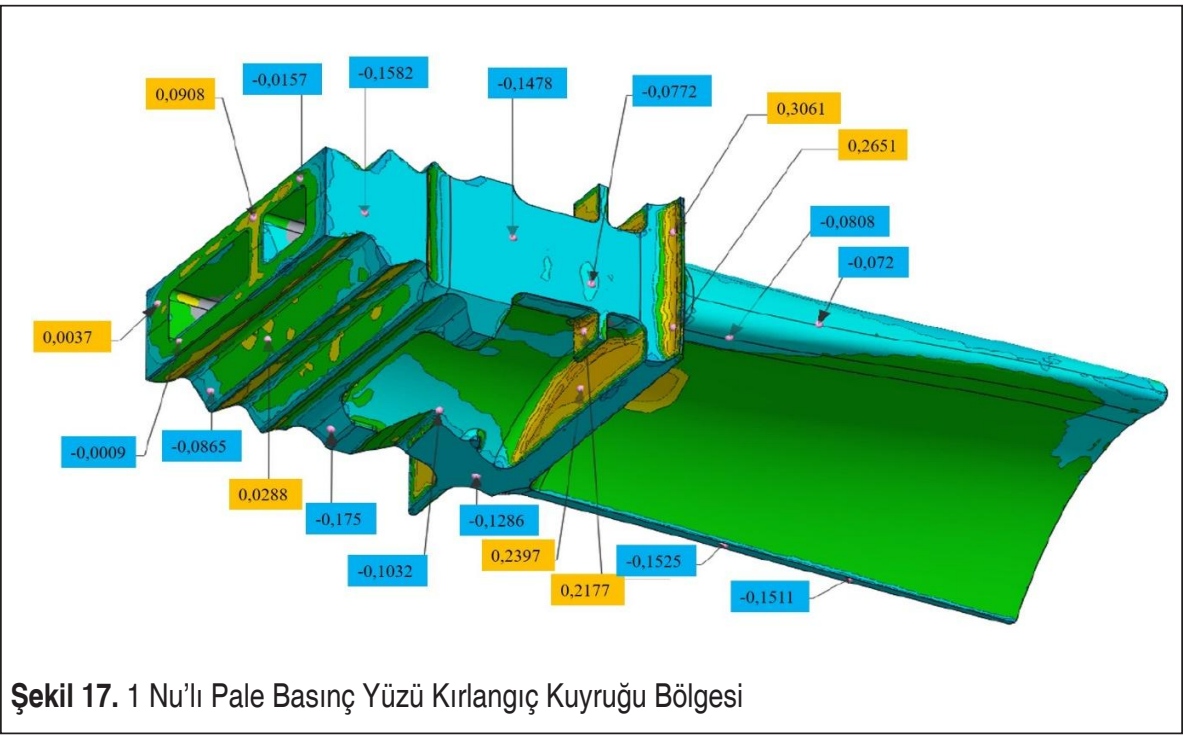

Şekil 17'de 1 Nu'lı pale ve Şekil 18'de 2 Nu'lı palelere ait basınç yüzü kırlangıç bölgelerine ait fotogrametrik ölçümler sunulmuştur.

Şekil 19' da sunulan kıyaslama grafiğinde görüldüğü üzere 1 ve 2 Nu'lı paleye ait basınç yüzü kırlangıç bölgelerinin geometrik olarak birbirlerine çok yakın bir profi-

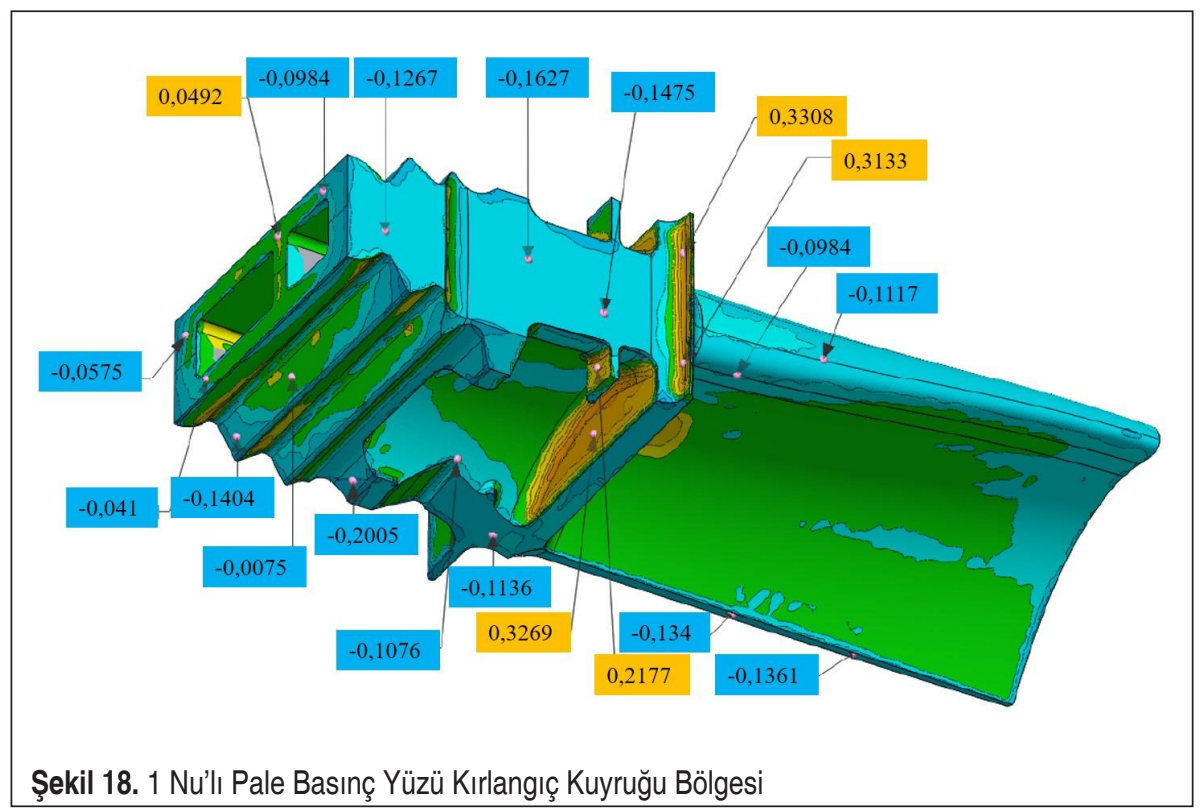




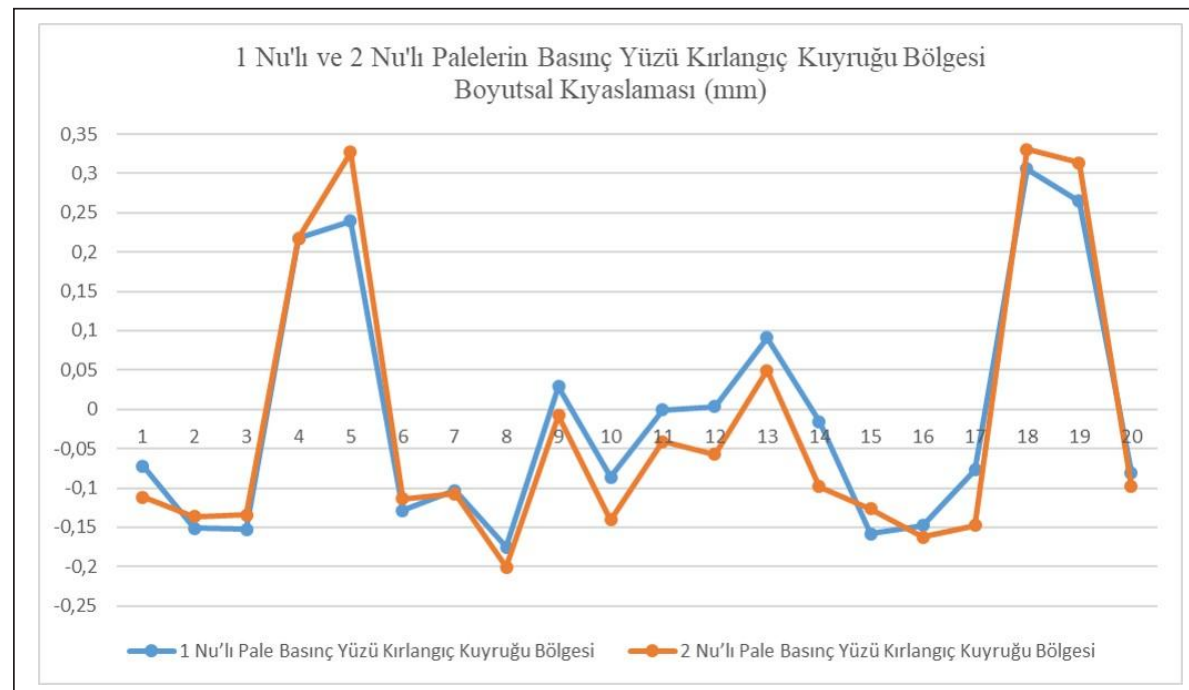

Şekil 19. 1 Nu’lı ve 2 Nu’lı Palelerin Basınç Yüzü Kırlangıç Kuyruğu Bölgesi Boyutsal Kıyaslaması

le sahip olduğu görülmektedir. Palelerin basınç yüzü kırlangıç bölgesi üzerinde elde edilen verilere göre; 40 adet ölçümden, 28 adet negatif değişimin ortalaması 0,10833 $\mathrm{mm}, 12$ adet pozitif değişimin ortalaması ise $0,19915 \mathrm{~mm}$ olarak gerçekleşmiştir. Her iki palenin basınç yüzü kırlangıç bölgelerinde meydana gelen değişim 0,012405 mm $(12,405 \mu)$ olarak gerçekleşmiştir.

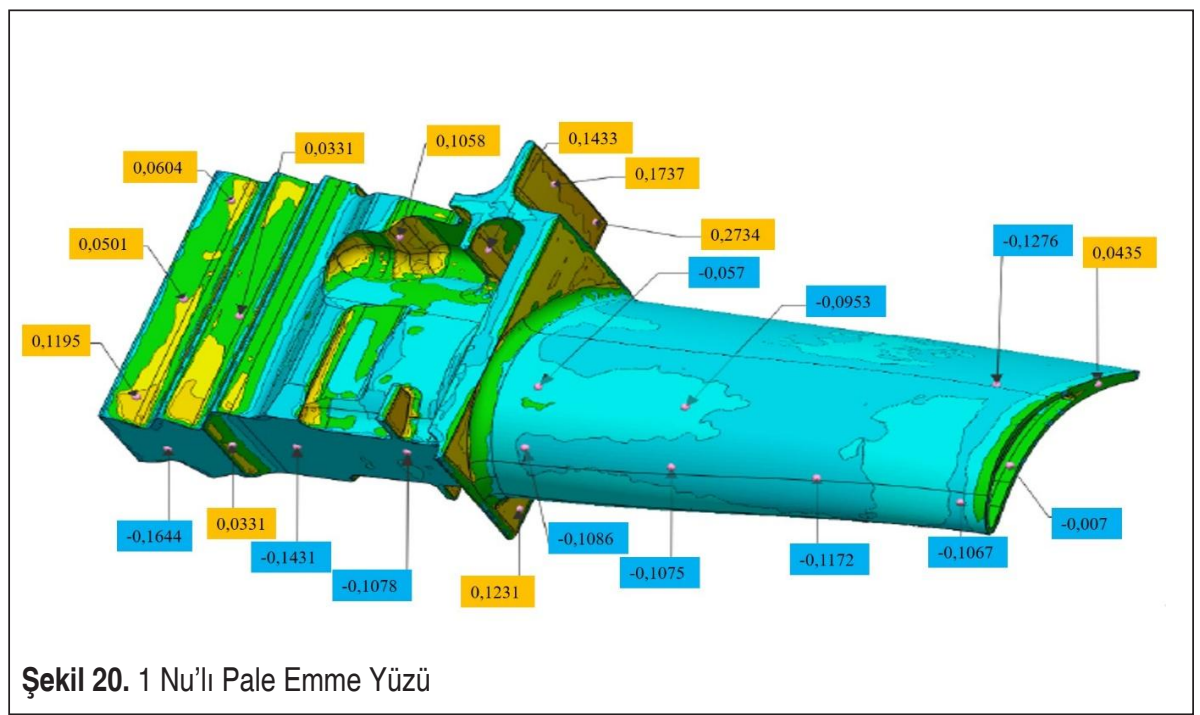




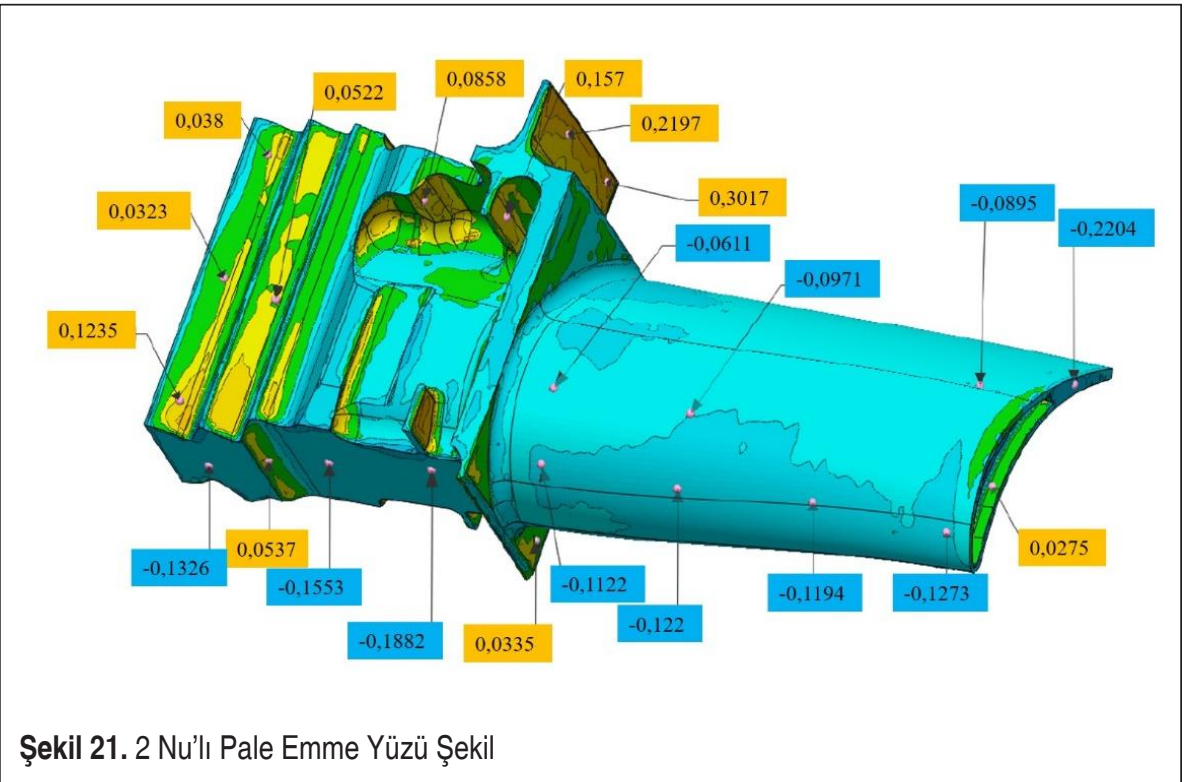

Şekil 20'de 1 Nu'lı pale ve Şekil 21'de 2 Nu'lı paleye ait emme yüzü bölgelerine ait fotogrametrik ölçümler sunulmuştur. Şekil 22'de sunulan kıyaslama grafiğinde görüldüğü üzere 1 ve 2 Nu'lı paleye emme yüzü bölgelerinin geometrik olarak birbirlerine çok yakın bir profile sahip oldukları görülmektedir.

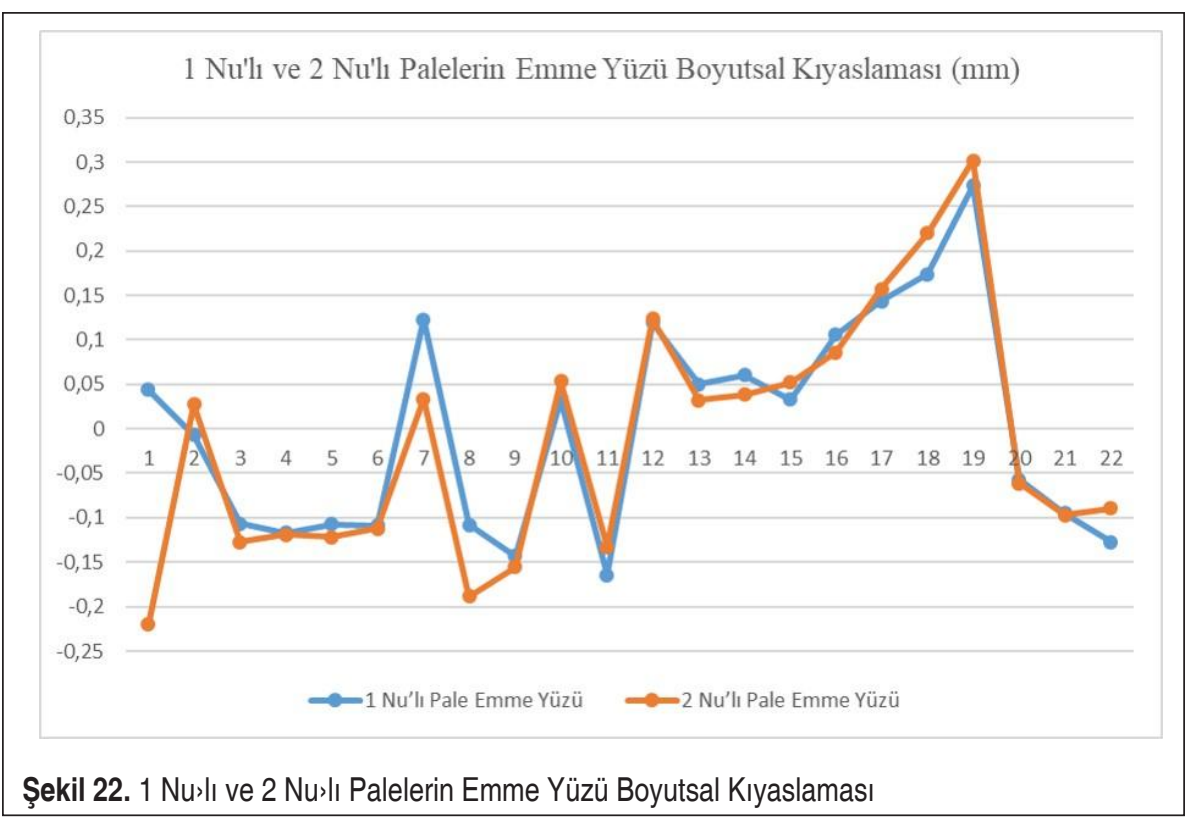




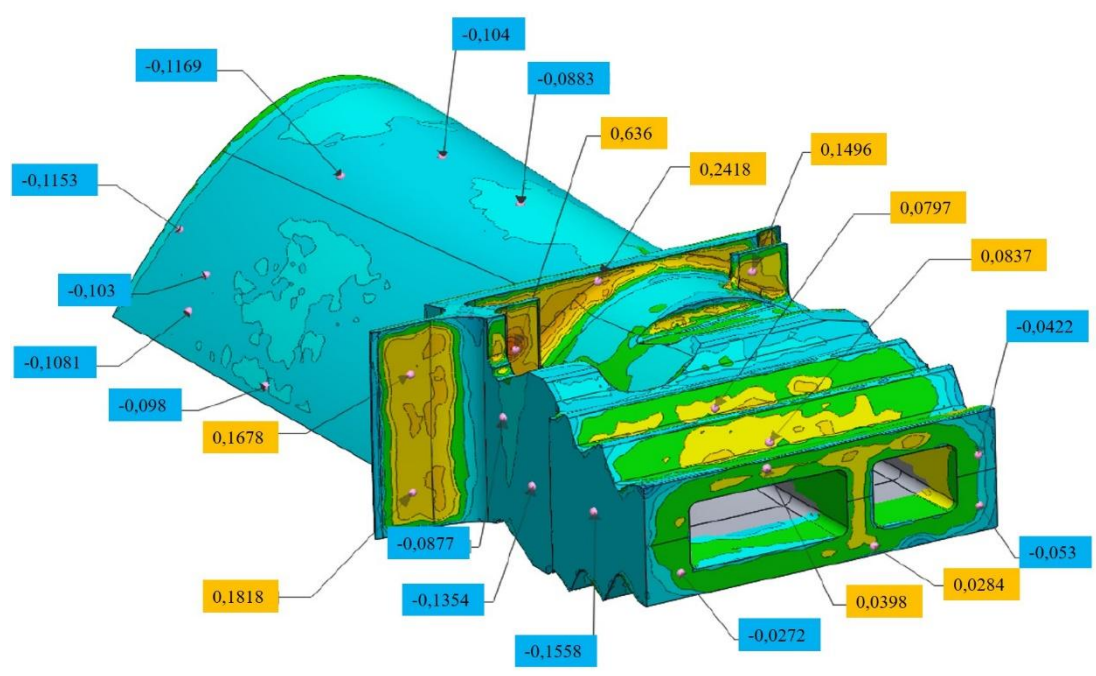

Şekil 23. 1 Nu’lı Pale Emme Yüzü Kırlangıç Kuyruğu Bölgesi

Palelerin emme yüzü üzerinde elde edilen verilere göre; 44 adet ölçümden, 22 adet negatif değişimin ortalaması $0,1167 \mathrm{~mm}, 22$ adet pozitif değişimin ortalaması ise 0,103814 mm olarak gerçekleşmiştir. Her iki palenin basınç yüzü kırlangıç bölgelerinde meydana gelen değişim $0,013873 \mathrm{~mm}(13,873 \mu)$ olarak gerçekleşmiştir.

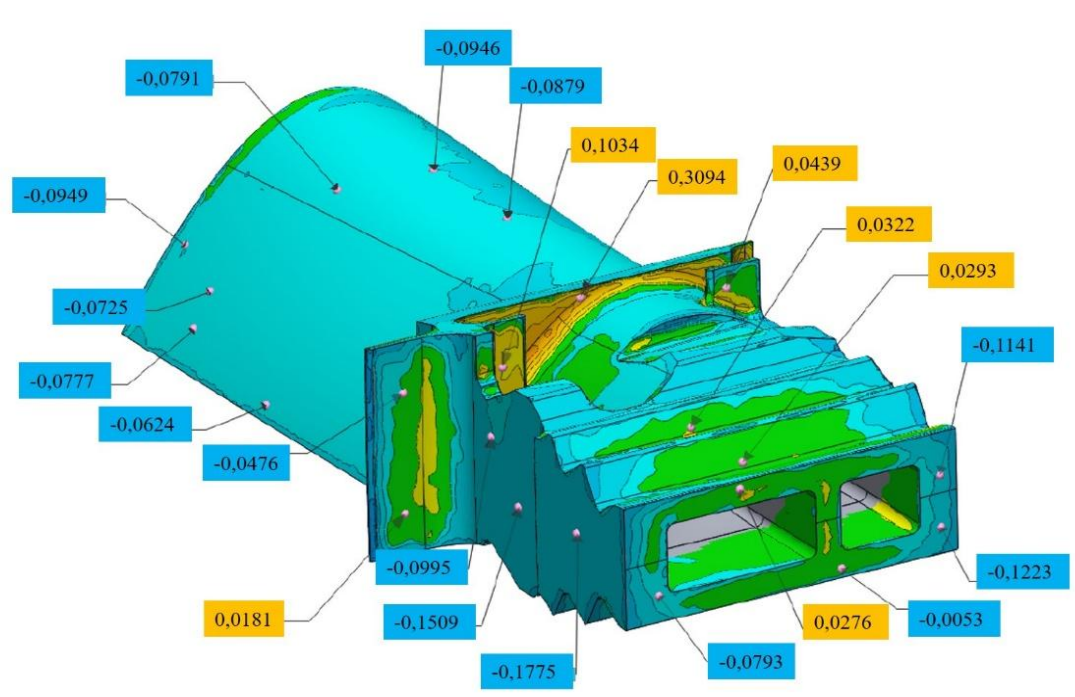

Şekil 24. 2 Nu’lı Pale Emme Yüzü Kırlangıç Kuyruğu Bölgesi 


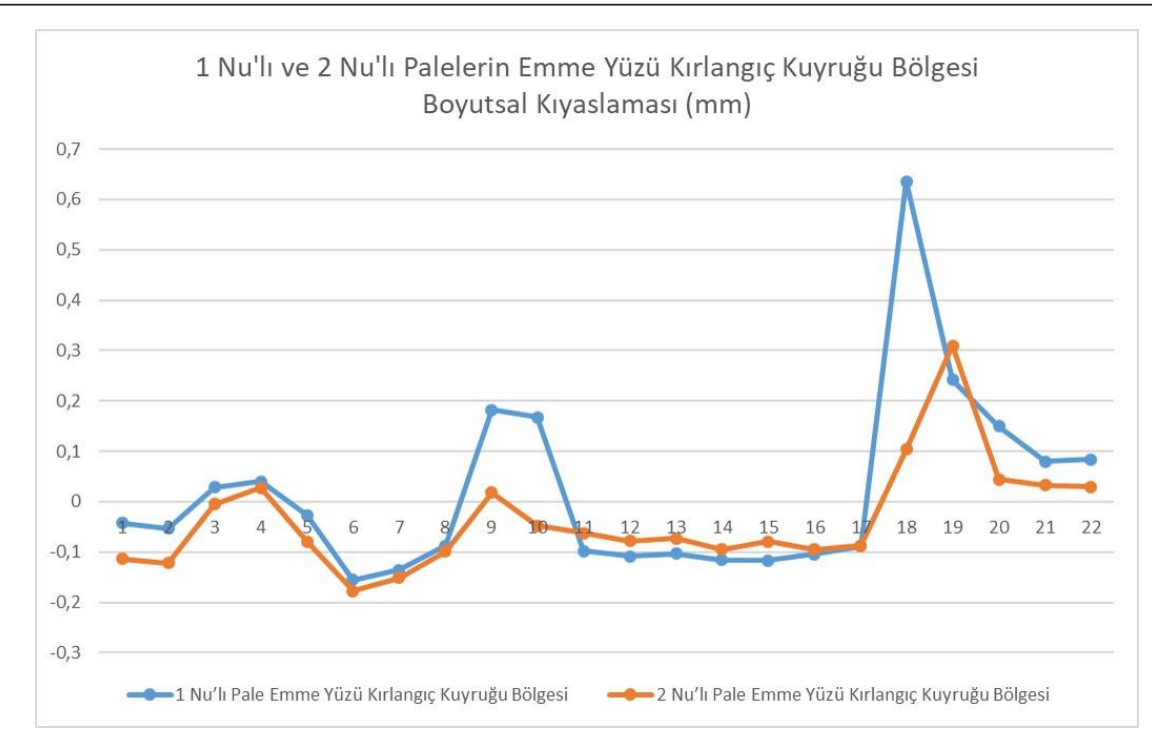

Şekil 25. 2 Nu’lı Pale Emme Yüzü Kırlangıç Kuyruğu Bölgesi

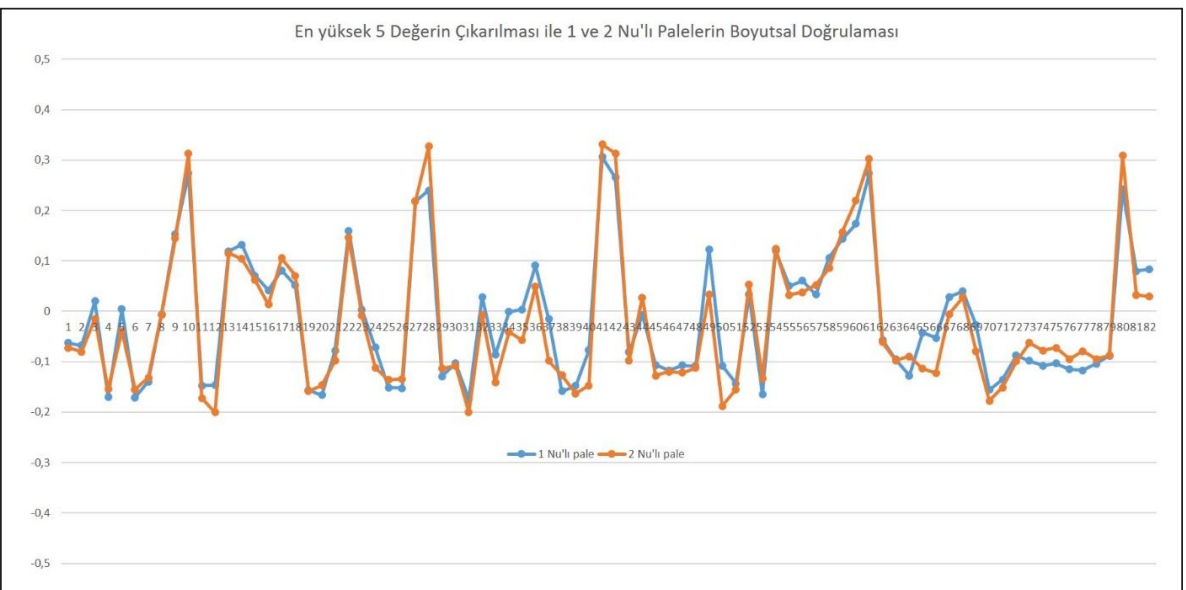

Şekil 26. 1 Nu’lı ve 2 Nu’lı Palelerin Emme Yüzü Kırlangıç Kuyruğu Bölgesi Boyutsal Kıyaslaması

Şekil 23'te 1 Nu'lı pale ve Şekil 24'de 2 Nu'lı palelerin emme yüzü kırlangıç bölgelerine ait fotogrametrik ölçümler sunulmuştur.

Palelerin emme yüzü kırlangıç bölgesi üzerinde elde edilen verilere göre; 44 adet ölçümden, 28 adet negatif değişimin ortalaması $0,09288 \mathrm{~mm}, 14$ adet pozitif değişimin ortalaması ise $0,155179 \mathrm{~mm}$ olarak gerçekleşmiştir. Her iki palenin basıç̧ yüzü 
kırlangıç bölgelerinde meydana gelen değişim $0,050159 \mathrm{~mm}(50,159 \mu)$ olarak gerçekleşmiştir. Şekil 25 'te sunulan kıyaslama grafiğinde görüldüğü üzere 1 ve $2 \mathrm{Nu}$ 'lı paleye ait emme yüzü kırlangıç kuyruğu genel itibariyle geometrik olarak birbirlerine yakın bir profile sahip olduğu gözlemlenmektedir.

İki geometri arasındaki farkın en büyük olduğu 5 değerin 4'ü emme yüzeyi kırlangıç kuyruğu bölgesinde sirasiyla $0,5326 \mathrm{~mm}, 0,2154 \mathrm{~mm}, 0,1637 \mathrm{~mm}$ ve $0,1057 \mathrm{~mm}$ ile 1 tanesi de emme bölgesi yüzeyinde $0,2639 \mathrm{~mm}$ olarak belirlenmiştir. Bu değerler hesaplamadan çıkarıldıktan sonra edilen grafik Şekil 26'da sunulmuş olup bu durumda, değişim değeri ortalama $0,007596 \mathrm{~mm}(7,59 \mu)$ olarak belirlenmiştir.

\section{SONUÇLAR}

Bir gaz türbin motoru kompresör palelerinin üretimi ve boyutsal doğruluğunun belirlenmesine yönelik çalışmada elde edilen sonuçlar aşağıdaki verilmiştir.

- Genel boyutsal kıyaslamada, negatif değişim gösteren 103 ölçümde ortalama $0,10634 \mathrm{~mm}$ ve pozitif değişim gösteren 71 ölçümde ortalama $0,127173 \mathrm{~mm}$ $(127,173 \mu) \mathrm{mm}$ olarak değişim görülmüştür.

- Negatif değişim en düşük 0,0009 mm, en yükssek 0,2204 mm olarak belirlenmiştir. Pozitif değişim ise $0,0029 \mathrm{~mm}$ en yüksek $0,636 \mathrm{~mm}$ olarak belirlenmiştir. Palelerin birbirine ortalama $0,02187 \mathrm{~mm}(21,87 \mu)$ değerinde yakınsadığı hesaplanmıştır.

- Ölçümlerde, katı modele oranla, 1 Nu'lı palede ortalama +0,0944/-0,0809 mm arasında, 2 Nu'lı palede ortalama $+0,1093 /-0,0978$ mm değişim olduğu belirlenmiştir.

- Pozitif ve yüksek değerli farklılıkların palelerin eğimli (Curved) yüzeylerinden daha ziyade düz (Flat) bölgelerinde gerçekleştiği görülmüştür. Bu durumun dikey inşa yönünde EÜ karakteristiklerinin daha kararlı sonuçlar vermesinden kaynaklandığı değerlendirilmektedir.

- Her iki palenin katı modele göre kıyaslamasında $\pm 0,05 \mathrm{~mm}$ limiti dâhilinde olduğu yeşil bölgelerin fazla olması üretimde tutarlılık açısından bir gösterge olarak nitelendirilmektedir.

- Müşteri talepleri doğrultusunda söz konusu veriler limit dâhilinde kabul edilmesi mümkündür. Ayrıca başka bir çalışmada tamamen mukavemet değerlerine odaklanarak deneyler gerçekleştirilmesi uygun olacaktır.

- Ortaya çıkan boyutsal farklılıkların bertaraf edilmesi ve istenen boyutsal değerde parça imalatı için katman kalınlığı, lazer gücü, tarama hızı, yanal kayma kalınlığ gibi parametrelerin tezgâh ile uyumlu olarak optimize edilmesi ve enerji yoğunluğu eşitliğini esas alarak üretim gerçekleştirilmesi önerilmektedir. 
- Bir hipotez olarak, daha sonraki üretimlerde, bu üretim sirasinda desen olarak kullanılan dişa doğru ilerleme (Off-Set Out) yerine, fraktal desenin seçilmesinin Şekil 6'da verilen yüzey deformasyonlarının minimize edilmesi açısından fayda sağlayacağı ön görülmektedir.

\section{TEŞEKKÜR}

$\mathrm{Bu}$ çalışma Artuk Aviation Ltd. Şti tarafından ilk ürün kontrolü çalışmaları kapsamında gerçekleştirilmiştir. Çalışmanın gerçekleştirilmesinde verilen destek için Artuk Aviation Ltd. Şti.'ne teşekkür ederim.

\section{KAYNAKÇA}

1. Peter, S. 2003. "Gas turbine technology", Physics Education, vol: 38, p. 504-511, DOI:10.1088/0031-9120/38/6/002

2. Mitsuhiro, T., Masashi K. 2014. "Making Lighter Aircraft Engines with Titanium Aluminide Blades", IHI Engineering Review, vol:47, p. 10-13

3. Burgi, Y. P., Caillet, M., \& Haefeli, S. 2002. "Field temperature measurements at Erta'Ale Lava Lake, Ethiopia”, Bulletin of Volcanology", vol: 64, p. 472-485. doi:10.1007/ s00445-002-0224-3

4. Ma, F., Cao, W., Luo, Y., Qiu Y. 2016. "The review of manufacturing technology for aircraft structural part”, Procedia CIRP, vol: 56, p. 594-598, https://doi.org/10.1016/j. procir.2016.10.117.

5. Noh, H.M., Benito A., Alonso G. 2016, "Study of the current incentive rules and mechanisms to promote biofuel use in the EU and their possible application to the çivil aviation sector" Transportation Research Part D: Transport and Environment, vol: 46, p. 298-316, https://doi.org/10.1016/j.trd.2016.04.007.

6. Kenaroğlu, Y. 2010. "Hava Araçlarının Uçuşa Elverişlilik Sertifikasyonu”. Mühendis ve Makina. 52, 614, 16-28.

7. Saraçyakupoğlu, T. 2020. Emniyet İrtifasından Bilgiler: Genel Havacılık, Üretim ve Bakım Süreçleri. ISBN: 978-625-402-030-8, Nobel Akademik Yayıncılık, Ankara.

8. Sivil Havacılık Genel Müdürlüğü (SHGM), 2018, "Havacılıkta Parça ve Cihaz Sertifikasyonu Rehber Dokümanı”, p. 14

9. Şöhret Y.,Ekici S.,Altuntaş Ö., Hepbaşlı A., Karakoç T.H. 2016, "Exergy as a useful tool for the performance assessment of aircraft gas turbine engines: A key review", Progress in Aerospace Sciences, Vol: 83, p. 57-69, https://doi.org/10.1016/j.paerosci.2016.03.001

10 Zhang, L., \& Chen, L. 2019. "A Review on Biomedical Titanium Alloys: Recent Progress and Prospect". Advanced Engineering Materials. Vol: 21, p. 1-29, doi:10.1002/ adem. 201801215 
11. Shuhui, H., Yingying, Z., Debin, S. 2013."Application of thermohydrogen processing to Ti6Al4V alloy blade isothermal forging". Materials Science and Engineering: A, Vol: 561, p. 17-25. doi:10.1016/j.msea.2012.10.056

12. Zhuang, J.-R., Lee, Y.-T., Hsieh, W.-H., \& Yang, A.-S. 2018. "Determination of melt pool dimensions using DOE-FEM and RSM with process window during SLM of Ti6Al4V powder". Optics \& Laser Technology, vol: 103, p. 59-76. doi:10.1016/j.optlastec.2018.01.013

13. Greitemeier, D., Palm, F., Syassen, F., \& Melz, T. (2017). Fatigue performance of additive manufactured TiAl6V4 using electron and laser beam melting. International Journal of Fatigue, Vol: 94, p. 211-217. doi:10.1016/j.ijfatigue.2016.05.001

14. Liu, R., Wang, Z., Sparks, T., Liou, F., \& Newkirk, J. 2017. “Aerospace applications of laser additive manufacturing”. Laser Additive Manufacturing, p. 351-371. doi:10.1016/ b978-0-08-100433-3.00013-0

15. Han, P. 2017. “Additive Design and Manufacturing of Jet Engine Parts". Engineering, vol:3(5), p. 648-652. doi:10.1016/j.eng.2017.05.017

16. Xu, X., Lu, Y., Li, S., Guo, S., He, M., Luo, K., Lin, J. 2018. “Copper-modified Ti$6 \mathrm{Al} 14 \mathrm{~V}$ alloy fabricated by selective laser melting with pro-angiogenic and anti-inflammatory properties for potential guided bone regeneration applications". Materials Science and Engineering: C, vol: 90, p. 198-210. doi:10.1016/j.msec.2018.04.046

17. Urtekin, L., Keleş, Ö. 2019. "Biyomedikal Uygulamalar İçin TiN Kaplı Ti6A14V Alaş1mının Mekanik Özelliklerinin Araştırılması”. Savunma Bilimleri Dergisi. vol: 18 (2), pp. 91-108. DOI: 10.17134/khosbd.642142

18. Seabra, M., Azevedo, J., Araújo, A., Reis, L., Pinto, E., Alves, N., Santos R., Mortágua, J. P. 2016. "Selective laser melting (SLM) and topology optimization for lighter aerospace componentes". Procedia Structural Integrity, Vol: 1, p. 289-296. doi:10.1016/j.prostr.2016.02.039

19. Farooq, M.U., Ali, M.A., He, Y., Khan, A.M., Pruncu, C.I., Kashif, M., Ahmed, N., Asif, N. 2020. "Curved profiles machining of Ti6A14V alloy through WEDM: investigations on geometrical errors". Journal of Materials Research and Technology, vol: 9 (6), p. 16186-16201,https://doi.org/10.1016/j.jmrt.2020.11.067

20. Garmendia, I., Flores, J., Madarieta, M., Lamikiz, A., Uriarte, L.G., Soriano, C. 2020. "Geometrical control of DED processes based on 3D scanning applied to the manufacture of complex parts." 11th CIRP Conference on Photonic Technologies. 7-10 Eylül 2020, Almanya.

21. Li, M., Li, J., Yang, D., He. 2020. Dimensional Deviation Management for Selective Laser Melted Ti6A14V Alloy Blade". Frontiers in Materials. vol:7, p.1-10

22. Annamaria, G., Kazarian M., Martina F., Mehrpouya M. 2019, "Metal additive manufacturing in the commercial aviation industry: A review", Journal of Manufacturing Systems, vol: 53, p. 124-149, https://doi.org/10.1016/j.jmsy.2019.08.005

23. Saraçyakupoğlu, T. 2019. "Havacılık Endüstrisinde 3 Boyutlu Üretim Uygulamalarının Uçuşa Elverişlilik Kural ve Düzenlemelerine Göre Değerlendirilmesi”, International Journal of 3D Printing Technologies and Digital Industry, vol: 4, p. 53-65 
24. Yusuf S.M.,Cutler S., Gao N. 2019. "Review: The Impact of Metal Additive Manufacturing on the Aerospace Industry.", Metals, Vol: 9, p. 1286, doi:10.3390/met9121286

25. Gibson, I., Rosen, D., Stucker B. 2015. "Additive Manufacturing Technologies: 3D Printing, Rapid Prototyping, and Direct Digital Manufacturing”, ISBN 978-1-49392112-6, DOI 10.1007/978-1-4939-2113-3, Springer, New-York

26. Yamanaka, K., Saito, W., Mori, M., Matsumoto, H., Chiba, A. 2015. "Preparation of weak-textured commercially pure titanium by electron beam melting", Additive Manufacturing, vol: 8, p.105-109, http://dx.doi.org/doi:10.1016/j.addma.2015.09.007

27. Barroqueiro, B., Andrade-Campos, A., Valente, R.A.F. 2019. "Designing Self Supported SLM Structures via Topology Optimization" Journal of Manufacturing and Materials Processing, vol:3, p. 68, https://doi.org/10.3390/jmmp3030068

28. Rizzo, A., Goel, S., Luisa, G.M., Iglesias, R., Jaworska, L., Lapkovskis, V., Novak, P., Postolnyi, B.O., Valerini, D. 2020. "The Critical Raw Materials in Cutting Tools for Machining Applications: A Review.”, Materials. vol: 13, p. 1377, https://doi.org/10.3390/ ma13061377

29. Poyraz, Ö., Kuşhan M.C. 2018. "Havacılık Komponentlerinin Bakım Uygulamalarında Katmanlı İmalat Teknolojilerinin Kullanımı.”, Mühendis ve Makina, Vol. 59 (691), p. 59-69

30. Ateş, H., Düzgün M. 2020. "İnsansız Hava Araçları (İHA) Temel Bilgiler ve Kullanım Alanları", p. 144, ISBN: 978-625-406-738-9 Nobel Akademik Yayınc1lık, Ankara

31. American Society for Testing and Materials (ASTM) 1472, Standard Specification for Wrought Titanium -6Aluminum -4Vanadium Alloy (UNS R56400) for Surgical Implant Applications

32. American Society for Testing and Materials (ASTM) 2924, Standard Specification for Additive Manufacturing Titanium-6 Aluminum-4 Vanadium with Powder Bed Fusion

33. Jiménez, M., Romero, L., Domínguez, I.A., Espinosa, M.M., Domínguez, M. 2019. "Additive Manufacturing Technologies: An Overview about 3D Printing Methods and Future Prospects", Complexity, Vol: 2019, p.30, https://doi.org/10.1155/2019/9656938

34. Liu, S., Shin, Y.C. 2019. “Additive manufacturing of Ti6Al4V alloy: A review”, Materials and Design, Vol:164, p. 107552, https://doi.org/10.1016/j.matdes.2018.107552

35. Wang, M., Lin, X., Huang W. 2016. "Laser additive manufacture of titanium alloys", Materials Technology, Vol: 31, p. 90-97, DOI: 10.1179/1753555715Y.0000000079

36. Körner, C. 2016. "Additive manufacturing of metallic components by selective electron beam melting - a review", International Materials Reviews, Vol: 61, p. 361-377, DOI: 10.1080/09506608.2016.1176289

37. Herzog, D., Seyda V., Wycisk E., Emmelmann C. 2016. "Additive manufacturing of metals", Acta Materialia, Vol: 117, p. 371-392, https://doi.org/10.1016/j.actamat.2016.07.019

38. Becker, T., Mathias, B., Cornie, S. 2015. "Microstructure and mechanical properties of direct metal laser sintered TI-6AL-4V". South African Journal of Industrial Engineering, 
vol. 26. P. 1-10. 10.7166/26-1-1022.

39. Zhu, J., Zhou, H. Wang, C., Zhou L., Yuan S., Zhang W. 2021. “A review of topology optimization for additive manufacturing: Status and challenges", Chinese Journal of Aeronautics, Vol: 34, Issue 1, p. 91-110,https://doi.org/10.1016/j.cja.2020.09.020

40. Shamsdini, S., Shakerin, S., Hadadzadeh, A., Amirkhiz, B. S., Mohammadi, M. 2020. "A trade-off between powder layer thickness and mechanical properties in additively manufactured maraging steels". Materials Science and Engineering: A, vol: 776, p. 139041. doi:10.1016/j.msea.2020.139041

41. Shi, X., Ma, S., Liu, C., Chen, C., Wu, Q., Chen, X., Lu, J. 2016. "Performance of High Layer Thickness in Selective Laser Melting of Ti6Al4V”, Materials , vol:9, p. 975, https://doi.org/10.3390/ma9120975

42. Mierzejewska, Ż.A., Hudák, R., Sidun, J. 2019, "Mechanical Properties and Microstructure of DMLS Ti6Al4V Alloy Dedicated to Biomedical Applications", Materials, vol: 12, p.176, https://doi.org/10.3390/ma12010176

43. Agius, D., Kourousis, K.I., Wallbrink, C. 2018, "A Review of the As-Built SLM Ti6Al-4V Mechanical Properties towards Achieving Fatigue Resistant Designs", Metals, Vol: 8, p. 75, https://doi.org/10.3390/met8010075

44. Poyraz, Ö., Kuşhan, M.C. 2017. “ Metallerin lazer katmanlı imalatında farklı proses parametrelerin etkisinin incelenmesi “, Mühendislik ve Mimarlık Fakültesi Dergisi, Vol: 33, 729-742, DOI:10.17341/gazimmfd.416479

45. Sola, A., Nouri, A. 2019. "Microstructural porosity in additive manufacturing: The formation and detection of pores in metal parts fabricated by powder bed fusion", Vol: 1, p. 10021, DOI: 10.1002/amp2.10021

46. Bandyopadhyay A., Bose S. 2020. "Additive Manufacturing”, ISBN: 978-1-138-609259, Taylor \& Francis Group, New-York

47. Khairallah S.A., Anderson A.T., Rubenchik A., King W.E. 2016. "Laser powder-bed fusion additive manufacturing: Physics of complex melt flow and formation mechanisms of pores, spatter, and denudation zones", Acta Materialia, Vol: 108, p.36-45,https://doi. org/10.1016/j.actamat.2016.02.014

48. Vilardell, A.M., Yadroitsev, I., Yadroitsava, I., Albu, M., Takata, N., Kobashi, M., Krakhmalev, P., Kouprianoff, D., Kothleitner, G., Plessis, A.D. 2020. "Manufacturing and characterization of in-situ alloyed Ti6Al4V(ELI)-3 at.\% $\mathrm{Cu}$ by laser powder bed fusion", Additive Manufacturing, Vol:36, p. 101436, https://doi.org/10.1016/j.addma.2020.101436

49. Guo, Q., Zhao,C., Qu,M., Xiong, L., Escano, L.I., Hojjatzadeh, S.M.H., Parab, N.D., Fezzaa, K., Everhart, W., Sun, T., Chen, L. 2019. "In-situ characterization and quantification of melt pool variation under constant input energy density in laser powder bed fusion additive manufacturing process", Additive Manufacturing, Vol:28, p. 600-609,https://doi.org/10.1016/j.addma.2019.04.021 
50. Kusuma, C., Ahmed, S.H., Mian, A., Srinivasan R. 2017. "Effect of Laser Power and Scan Speed on Melt Pool Characteristics of Commercially Pure Titanium (CP-Ti)". Journal of Materials Engineering and Performance, vol: 26, p. 3560-3568, https://doi. org/10.1007/s11665-017-2768-6

51. Yu, N. 2005. Process Parameter Optimization for Direct Metal Laser Sintering (DMLS), Doktora tezi, National University of Singapore, Singapur

52. Shamsaei, N., Yadollahi, A., Bian, L., Thompson, S.M. 2015. "An overview of Direct Laser Deposition for additive manufacturing; Part II: Mechanical behavior, process parameter optimization and control", Additive Manufacturing, vol:8, p. 12-35, https://doi. org/10.1016/j.addma.2015.07.002

53. Yu, J., Lin, X., Ma, L., Wang, J., Fu, X., Chen, J., Huang, W. 2011. “Influence of laser deposition patterns on part distortion, interior quality and mechanical properties by laser solid forming (LSF)", Materials Science and Engineering: A, vol: 528, p. 1094-1104, https://doi.org/10.1016/j.msea.2010.09.078

54. Guzanová, A., Ižaríková, G., Brezinová, J., Živčák, J., Draganovská, D., \& Hudák, R. 2017. "Influence of Build Orientation, Heat Treatment, and Laser Power on the Hardness of Ti6Al4V Manufactured Using the DMLS Process", Metals, Vol: 7(8), 318. doi:10.3390/met7080318

55. Leuders, S., Thöne, M., Riemer, A., Niendorf, T., Tröster, T., Richard, H. A., Maier, H. J. 2013. "On the mechanical behaviour of titanium alloy TiAl6V4 manufactured by selective laser melting: Fatigue resistance and crack growth performance". International Journal of Fatigue, Vol: 48, p. 300-307. doi:10.1016/j.ijfatigue.2012.11.011

56. Flower, H. M. 1995. "High performance materials in Aerospace". ISBN: 978-94-0104296-3. DOI:10.1007/978-94-011-0658-6.Springer. Londra, İngiltere.

57. Malefane, L.B. 2019. "Determination of the fatigue properties of Ti6Al4V (ELI) parts built by a direct metal laser sintering system with standard process parameters followed by post-processing treatments", Central University of Technology, Free State 